\title{
Radioterapia intersticial para o tratamento dos tumores encefálicos
}

\author{
Cláudio Fernandes Corrêa \\ Trabalho realizado no Hospital Nove de Julho, Hospital Alemão Oswaldo Cruz, Hospital Sírio Libanês, Hospital \\ Samaritano, Hospital São Camilo, Hospital Beneficência Portuguesa de Santos, Casa de Saúde de Santos e \\ Hospital Nossa Senhora de Lourdes. Baseado na tese apresentada à Universidade Federal de São Paulo/Escola \\ Paulista de Medicina para obtenção do Título de Doutor em Medicina
}

\begin{abstract}
RESUMO
É apresentado o resultado do tratamento com radioterapia intersticial de 138 doentes com lesões neoplásicas encefálicas. Foram avaliados 50 doentes com glioblastoma multiforme, $45 \mathrm{com}$ gliomas de baixo grau, $19 \mathrm{com}$ astrocitomas anaplásicos, $23 \mathrm{com}$ metástases e $1 \mathrm{com}$ meningioma. Os resultados foram avaliados em relação a sexo, idade, índice de Karnofsky à época da execução do procedimento, volume e localização das lesões e realização ou não de craniotomia, radioterapia e quimioterapia como complemento ao procedimento.

Concluiu-se que a radioterapia intersticial é procedimento seguro, simples e eficaz para o tratamento de neoplasias sediadas no encéfalo.
\end{abstract}

\section{PALAVRAS-CHAVE}

Braquiterapia. Radioterapia. Tumores encefálicos.

\begin{abstract} It is concluded that the procedure is safe and efficient.

\section{KEYWORDS}

Brachytherapy. Radiotherapy. Brain tumors.
\end{abstract}

Interstitial radiotherapy for treatment of brain tumors

The purpose of this study was to evaluate the efficacy of brachytherapy in the treatment of lowgrade glioma, high-grade glioma, metastasis and meningioma. One hundred thirty eight patients were treated. Fifty patients presented glioblastoma multiform, 45 low grade gliomas, 19 anaplastic astrocytomas, 23 metastasis, and one patient had meningioma.

The results were accessed in relation to gender, age and Karnofsky index of the patients, volume and topography of the lesion, and association with craniotomy, radiotherapy and or chemotherapy.

\section{Introdução}

As neoplasias do encéfalo estão entre a sexta e oitava causas mais freqüentes de lesões intracranianas dos adultos e a segunda causa mais comum de doença neurológica crônica em pediatria. Os tumores primários do encéfalo correspondem a $2 \%$ dos óbitos provocados pelo câncer. São responsáveis por $20 \%$ dos tumores malignos diagnosticados antes dos 15 anos de idade e por, aproximadamente, $30 \%$ das mortes na sociedade ocidental $^{118}$.

Graças à adoção de recursos tecnológicos mais apropriados, à execução de intervenções terapêuticas precoces e à adoção de tratamentos adjuvantes mais adequados, os resultados das terapias para as neoplasias encefálicas tornaram-se mais favoráveis. Entre esses recursos, destacam-se a delineação das lesões com novas técnicas de aquisição de imagem acopladas aos princípios de estereotaxia, a neuronavegação, a eletrofisiologia intra-operatória, a ressonância magnética realizada durante o ato operatório e as conquistas recentes nas áreas de quimioterapia, radioterapia, biologia molecular e genética dos tumores encefálicos.

Entretanto, apesar do entusiasmo com a aplicação dos novos conhecimentos em neurooncologia - como a terapia gênica e a imunoterapia -, os procedimentos clássicos fundamentados em cirurgias radicais ou paliativas e em radioterapia e, eventualmente, em quimioterapia são ainda os melhores instrumentos para o tratamento da maioria das lesões neoplásicas primárias ou secundárias do encéfalo. Desses, os procedimentos de radioterapia são considerados um dos mais efetivos, isoladamente ou complementando tratamentos cirúrgicos ou quimioterápicos ${ }^{22}$. 
A radioterapia intersticial, ou braquiterapia, ou radiocirurgia intersticial, é um procedimento que possibilita a aplicação de elevada dose de radiação limitada a volumes definidos de tumores, com pouco comprometimento dos tecidos adjacentes. Apesar de ser aplicado desde o início do século XX, somente nos últimos 25 anos - após o desenvolvimento de isótopos mais seguros, apresentados sob configuração mais apropriada, e de sistemas de planejamento mais precisos - esse procedimento tornou-se alternativa atraente e praticado em algumas unidades de radioterapia e de neurocirurgia.

A radioterapia intersticial consiste na irradiação intralesional, com doses e taxas de doses variadas, durante segundos, minutos, horas, dias, semanas, meses e, às vezes, permanentemente. A possibilidade de irradiação com baixa taxa de dose e elevada dose total são algumas vantagens da radioterapia intersticial sobre a telerradioterapia convencional.

A dose e a taxa de dose são determinantes fundamentais do efeito biológico da radiação ionizante ${ }^{17,27,97,98,95,96,97,98,100,105,116,132,133,153,194,217,232,233}$. A redução da taxa de dose e o aumento do tempo de exposição amenizam os efeitos biológicos indesejáveis. Demonstrouse que, a partir de certa dose, a fração relativa de sobrevida celular decresce exponencialmente ${ }^{173}$.

A resistência das células hipóxicas à radiação ionizante aguda é, aproximadamente, três vezes maior que a das células normóxicas (razão de intensificação do oxigênio - RIOx $)^{41,99}$. Hall e cols. ${ }^{94}$ demonstraram que, frente à mesma dose de irradiação, a RIOx das células de mamíferos irradiadas continuamente com baixa taxa dose $(32 \mathrm{cGy} / \mathrm{h})$ é menor que a das células tratadas com alta taxa de dose. Essa é a razão pela qual morrem mais células tratadas com baixa taxa de dose continuamente que com alta taxa de dose, dentro de certos limites. A irradiação prolongada à baixa taxa de dose converte frações de células hipóxicas em frações normóxicas que, por sua vez, são mais sensíveis à

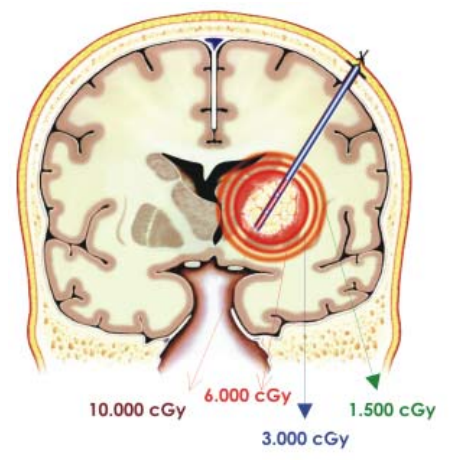

A irradiação. Van Putten e Kallman ${ }^{221}$ observaram que, após a irradiação fracionada, sarcomas de ratos com coeficiente hipóxico celular de $14 \%$ mantêm a fração hipóxica em $14 \%$, indicando que com a morte das células normóxicas as células hipóxicas tornam-se normóxicas, sendo mantida a proporção dos dois componentes. Observaram, também, que o processo de reoxigenação completa-se em menos que 24 horas. A permanente reoxigenação das células tumorais e a dependência menor da oxigenação celular (RIOx mais baixo) são razões que tornam a radioterapia intersticial mais eficaz que a telerradioterapia para o tratamento das neoplasias. Durante tratamento a longo prazo, as células sobreviventes podem proliferar e anular o benefício proporcionado pela morte celular, o que dificulta a esterilização do tumor. Quando a dose é superior à crítica, a repopulação deixa de ser elemento importante, pois a repopulação dos tecidos sadios é mais rápida que a dos tecidos neoplásicos.

Pode-se, portanto, concluir que a irradiação contínua com a baixa taxa de dose é superior à irradiação fracionada com alta taxa de dose porque maximiza a razão terapêutica sobre os tecidos neoplásicos e poupa os tecidos normais; ou seja, a razão terapêutica é melhorada. A radiação contínua com taxa de dose baixa poupa os tecidos normais dos efeitos lesivos porque aqueles repararam o dano subletal (DSL) com mais eficiência. A radioterapia intersticial requer fração de RIOx mais baixa que as altas taxas de dose em regimes fracionados para alcançar mesmo grau de morte celular, possibilita repopulação mais rápida no tecido normal que no neoplásico e proporciona sincronização das células tumorais nas fases $\mathrm{G} 2$ e M. O implante de uma fonte radioativa no interior de um tumor proporciona administração de dose máxima de irradiação no tumor e mínima agressão aos tecidos normais vizinhos; a dose absorvida é inversamente proporcional ao quadrado da distância entre a fonte e o tecido (Figura 1). O índice de



B

Figura 1 - A: Representação gráfica da secção coronal do cérebro com um tumor irradiado com 10.000 cGy na periferia da lesão por implante intralesional temporário de ${ }^{125} \mathrm{I}$. A dose em vários pontos do tumor demonstra que os efeitos da irradiação seguem a lei do inverso do quadrado da distância e da atenuação por absorção no tecido. B: Dosimetria para o mesmo tumor tratado pela telerradioterapia fracionada. $O$ encéfalo recebeu 4.500 cGy e o tumor, dose de reforço de 6.000 cGy. 
atenuação da radiação é determinado pela densidade do tecido e pela energia da fonte de radioatividade: quanto menos energia apresentar o isótopo, menos tecido será penetrado; quanto mais denso for o tecido, menor será a penetração da radiação.

Muitos isótopos são, ou foram, empregados para a radioterapia intersticial. Os mais importantes são relacionados no quadro 1 . O isótopo ideal deve apresentar meia-vida longa, emitir raios $\gamma$ de energia baixa, ser de baixo custo e apresentar pequeno risco de contaminação do pessoal que o manipula e que cuida dos doentes. O mais utilizado atualmente para o tratamento de tumores do encéfalo, cabeça, pescoço, próstata, pulmão e útero é o ${ }^{125} \mathrm{I}$. $\mathrm{O}{ }^{125} \mathrm{I}$ emite radiação $\gamma$ com energia de apenas 28 a $34 \mathrm{KeV}$ (Kilo-elétron-volts), tem meio-valor no chumbo de $0,025 \mathrm{~mm}$, meio-valor nos tecidos de apenas 2 centímetros e meia-vida de 60,2 dias ${ }^{120,128}$. O decréscimo rápido no tecido possibilita que os danos no tecido vizinho ao tumor sejam mínimos. É apresentado sob a forma de cápsulas radiopacas que absorvem a radiação $\alpha$, a maior parte da radiação $\beta$ e pouca radiação $\gamma$ e em dimensões que possibilitam a sua introdução em dispositivos de pequenas dimensões no interior das lesões.

\begin{tabular}{lcccc}
\hline \multicolumn{5}{c}{ Quadro 1 } \\
Radioisótopos mais empregados para \\
radioterapia intersticial \\
\hline Isótopo & Meia-vida Radiação $\boldsymbol{\alpha}$ Radiação $\beta$ Radiação $\boldsymbol{\gamma}$ \\
& & & & $(\mathrm{KeV})$ \\
\hline Rádio-226 $\left({ }^{226} \mathrm{Ra}\right)$ & 1.064 anos & + & + & $180-2.200$ \\
Radônio-222 $\left({ }^{222} \mathrm{Rn}\right)$ & 3,8 dias & + & + & $220-2.200$ \\
Ouro-198 $\left({ }^{198} \mathrm{Au}\right)$ & 2,7 dias & - & + & 410 \\
Ítrio-90 $\left({ }^{90} \mathrm{Y}\right)$ & 2,7 dias & - & + & \\
Fósforo-32 $\left({ }^{32} \mathrm{P}\right)$ & 14,4 dias & - & + & 660 \\
Césio-137 $\left({ }^{137} \mathrm{Cs}\right)$ & 30 anos & - & + & $1.170-1.330$ \\
Cobalto-60 $\left({ }^{60} \mathrm{Co}\right)$ & 5,3 anos & - & & $300-610$ \\
Irídio-192 $\left({ }^{192} \mathrm{Ir}\right)$ & 74,2 dias & - & + & $28-35$ \\
Iodo-125 $\left({ }^{125} \mathrm{I}\right)$ & 60,2 dias & - & & \\
\hline
\end{tabular}

A distribuição angular e as superfícies anisotrópicas das curvas de isodose foram determinadas para a maioria das fontes não-puntiformes por métodos empíricos e, mais recentemente, por computador $^{5,109,138,176}$ (Figura 2). Conhecendo-se o fator de atenuação nos tecidos, pode-se calcular a dose exata administrada na periferia do tumor e o tempo de exposição necessário para atingir a dose planejada.

\section{Casuística e método}

Nossa experiência é baseada na observação de 138 doentes com tumores encefálicos tratados com

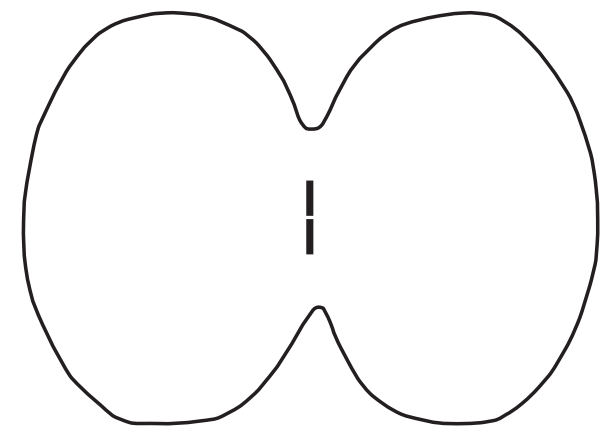

Figura 2 - Distribuição angular (isodose) de duas fontes de ${ }^{125} \mathrm{I}$ no interior de um tubo.

radioterapia intersticial no Hospital Nove de Julho, Hospital Alemão Oswaldo Cruz, Hospital Sírio Libanês, Hospital Samaritano, Hospital São Camilo, Hospital Beneficência Portuguesa de Santos, Casa de Saúde de Santos e Hospital Nossa Senhora de Lourdes, entre agosto de 1991 e junho de 1998. Todos os doentes e seus cuidadores foram informados quanto às vantagens e os riscos dos procedimentos e concordaram com a sua realização.

Receberam esse tratamento 45 doentes com astrocitomas de baixo grau, $19 \mathrm{com}$ astrocitomas anaplásicos, $50 \mathrm{com}$ glioblastoma multiforme, $23 \mathrm{com}$ metástases e 1 com meningioma. Os locais de origem das metástases estão representados na tabela 1. Das 23 metástases, 30,4\% eram de pulmão, $21,7 \%$ de órgãos não determinados e $17,4 \%$ de mama.

\begin{tabular}{|c|c|c|}
\hline \multicolumn{3}{|c|}{$\begin{array}{c}\text { Tabela } 1 \\
\text { Distribuição das fontes das metástases encefálicas dos } \\
\text { doentes tratados com radioterapia intersticial }\end{array}$} \\
\hline Origem da metástase & $\mathbf{N}$ & $\%$ \\
\hline Pulmão & 7 & 30,4 \\
\hline Mama & 4 & 17,4 \\
\hline Colo uterino & 2 & 8,7 \\
\hline Rim & 2 & 8,7 \\
\hline Reto & 1 & 4,3 \\
\hline Esôfago & 1 & 4,3 \\
\hline Tegumento & 1 & 4,3 \\
\hline Indeterminada & 5 & 21,7 \\
\hline Total & 23 & 100,0 \\
\hline
\end{tabular}

Todos os doentes foram internados e submetidos a exame clínico e neurológico e a determinação das incapacidades, inabilidades e déficits de acordo com o índice de Karnofsky (IK) inicial (IK1) e final (IK2) e ao exame de tomografia computadorizada (TC) e/ou ressonância magnética (RM) do encéfalo. As avaliações clínicas e os exames de imagem foram realizados imediatamente após o procedimento, no primeiro mês e, subseqüentemente, a cada 3 meses ou quando 
necessário. Os resultados foram quantificados em termos de índice de Karnofsky e tempo de sobrevida e comparados com aqueles descritos na literatura. As complicações dos procedimentos foram também registradas. Estudos estatísticos foram realizados de acordo com os preceitos técnicos convencionais.

\section{Procedimentos operatórios}

Com o aparelho estereotáxico (ETMO3B Micromar $^{\circledR}$, Diadema, São Paulo, Brasil) fixado ao segmento cefálico dos doentes, após realização de estereotomografia (estéreo-TC) com contraste iodado ou de estereorressonância magnética (estéreo-RM) em T1 com gadolínio, T2 e FLAIR do encéfalo, foram identificadas as lesões, calculados seus volumes e determinadas suas localizações e características morfológicas. Em alguns casos, as imagens de RM foram fundidas com as da estéreo-TC para delinear melhor os contornos das lesões, mantendo a precisão espacial da TC. Em doentes sem condições de cooperar, os procedimentos foram conduzidos sob sedação com fentanila, droperidol e midazolam ou, sob anestesia geral, com os mesmos agentes e inalação de $\mathrm{N}_{2} \mathrm{O}$. A aplicação do aparelho de estereotaxia ao crânio, as incisões e as trepanações foram realizadas nos demais doentes após a infiltração do tegumento com solução de lidocaína a $2 \%$. A reconstrução tridimensional das imagens, os cálculos estereotáxicos e as curvas de isodose foram realizados com o programa de computação Micromar Stereotactic Planning System ${ }^{\circledR}$ (MSPS) (Micromar, Diadema, São Paulo, Brasil). Os cálculos estereotomográficos foram empregados para determinar a localização das trepanações, os alvos das biópsias, a disposição espacial dos cateteres que sustentaram os isótopos e a situação desses no interior daqueles. O programa de computação também possibilitou calcular a duração da irradiação intersticial. Por meio de trepanações, biópsias seriadas das regiões representativas da lesão foram feitas nos doentes em que o diagnóstico não havia sido previamente estabelecido. O material de biópsia foi processado segundo técnica de congelação ou impressão, corado e examinado por neuropatologistas, no próprio centro cirúrgico. Amostras foram selecionadas, fixadas em solução de formol e, ulteriormente, processadas para realização de exames anatomopatológicos com corantes convencionais e, quando necessário, por colorações específicas ou imunoistoquímica. Os astrocitomas anaplásicos foram definidos como sendo os gliomas astrocitários que apresentam pleomorfismo celular $\mathrm{e}$ nuclear, mitoses abundantes e proliferação endotelial. Quando havia necrose, foram classificados como glioblastoma multiforme. Imediatamente a seguir, cateteres de nylon com 1,6 mm de diâmetro, selados na extremidade distal, foram implantados em pontos previamente definidos nas lesões, de acordo com a disposição espacial determinada pelo programa de computação, e fixados com metacrilato na dura-máter e na superfície de corte dos orifícios de trepanação (Figura 3). Em casos de carregamento intra-operatório de ${ }^{125} \mathrm{I}$, as sementes foram fixadas na luz dos cateteres e dispostas, de acordo com os cálculos previamente realizados e as feridas cirúrgicas suturadas, por planos, com pontos separados de nylon monofilamentado 4-0. Após período de observação de 12 a 24 horas, os doentes receberam alta hospitalar. A periferia das lesões identificadas foi tratada, de acordo com os métodos de imagem empregados, com $6.000 \mathrm{cGy}$. Ao completar o período necessário para atingir a dose de irradiação preconizada, os doentes foram readmitidos e, em regime ambulatorial, sob anestesia local ou, raramente, sob sedação ou anestesia geral, tiveram os cateteres de nylon e os isótopos removidos. Os ferimentos resultantes foram suturados com pontos separados de nylon monofilamentado 4-0, que foram removidos após transcorrido um período de 2 semanas.



Figura 3 - Radioterapia intersticial de tumor encefálico com técnica de carregamento intra-operatório com ${ }^{125}$ I.

A técnica de carregamento ulterior obedeceu à mesma seqüência de atos do procedimento previamente descrito. Os cateteres foram deixados exteriorizados pela ferida operatória, coberta com pomada de neomicina e bacitracina e ocluída com gaze. Em ambiente provido de proteção contra a irradiação, os cateteres foram, ulteriormente, carregados com fios de ${ }^{192} \mathrm{Ir}$, e os doentes foram mantidos internados durante o período apropriado para que a dose da irradiação planejada fosse administrada. Após essa fase, obedecendo ao descrito nos casos de carregamento intra-operatório, 
os cateteres foram removidos. Nos casos tratados com técnica hiperfracionada de carregamento ulterior de ${ }^{192} \mathrm{Ir}$ com alta taxa da dose, o deslocamento das sementes dos isótopos no interior dos cateteres foi realizado com o equipamento Nucleotron ${ }^{\circledR}$.

\section{Cálculo do volume dos tumores}

O volume dos tumores foi calculado por aproximação. Foram considerados como elipsóides de rotação com raios $\mathrm{R}_{1}$ e $\mathrm{R}_{2}$. Sendo o eixo de simetria de rotação do elipsóide paralelo ao raio $\mathrm{R}_{2}$, o volume foi calculado com o uso da fórmula:

$$
\mathrm{V}=4 / 3 \cdot \pi \cdot \mathrm{R}_{1}^{2} \cdot \mathrm{R}_{2}
$$

\section{Protocolo de quimioterapia}

Em alguns doentes com astrocitoma anaplásico ou glioblastoma multiforme foi realizada a quimioterapia. A administração de carmustina (BCNU, Becenum ${ }^{\circledR}$ ) na dose de $220 \mathrm{mg} / \mathrm{m}^{2}$, por via intravenosa, no dia da execução da radioterapia intersticial foi seguida da administração intravenosa de CDDP (Cisplatina ${ }^{\circledR}$ ), na dose de $20 \mathrm{mg} / \mathrm{m}^{2}$, uma vez por semana, durante o período de manutenção do implante de ${ }^{125} \mathrm{I}$, ou de $100 \mathrm{mg} / \mathrm{m}^{2}$, no dia do implante de ${ }^{192} \mathrm{Ir}$. A manutenção foi realizada com carmustina administrada por via intravenosa, na dose de $220 \mathrm{mg} / \mathrm{m}^{2}$, a cada 6 semanas, e procarbazina, por via oral, na dose de $100 \mathrm{mg} / \mathrm{m}^{2}$, a cada 3 semanas. A cada quatro ciclos os doentes foram reavaliados.

\section{Características dos isótopos utilizados}

$\mathrm{O}^{125} \mathrm{I}$ foi utilizado com a forma Medi-Physics, Inc., IMC - 6702 (Figura 4), apresentado em sementes com $4,5 \mathrm{~mm}$ de comprimento e $0,8 \mathrm{~mm}$ de diâmetro externo, contendo iodo incorporado em pequenas esferas de resina de intercâmbio aniônico. $\mathrm{O}$ revestimento da cápsula foi de titânio. A taxa de variação do Kerma foi de 5,44 a 45,2 $\mathrm{mGy} \mathrm{m}^{2} / \mathrm{h}$ ou $4,32 \mathrm{mCi}$ a $35,9 \mathrm{mCi}$. O ${ }^{192} \mathrm{Ir}$ foi empregado como fios contendo núcleo de ${ }^{192} \mathrm{Ir}$ no interior de uma cápsula cilíndrica de platina com o diâmetro de $0,1 \mathrm{~mm}$. A atividade aparente inicial aproximada foi de $0,3 \mathrm{mCi} / \mathrm{mm}$.

\section{Análise estatística}

Para caracterizar a amostra, as informações foram resumidas em freqüências e porcentagens, em caso de variáveis qualitativas, e em forma de médias, medianas e desvios-padrões mínimos e máximos, em caso de variáveis quantitativas.

Para estudar a evolução, foi realizada a análise da sobrevida total dos doentes desde o início da sintomatologia, considerando-se, como evento de interesse, o óbito. Esse tipo de análise considerou a evolução durante todo o período de observação, e não apenas os resultados finais.

Inicialmente, foram calculadas as probabilidades de sobrevida desde o início da sintomatologia para o total de doentes utilizando o método de Kaplan-Meier. Este método possibilitou a construção de curvas com as estimativas das probabilidades de sobrevida em função do tempo de observação. Assim, foi possível estabelecer a possibilidade temporal de sobrevida de um doente.

Para avaliar a influência de algumas variáveis na evolução, foram organizadas curvas de Kaplan-Meier para as categorias de cada variável. A conformação das curvas possibilitou comparar a evolução dos doentes segundo sexo, idade, diagnóstico, índice de Karnofsky inicial, localização da lesão, procedimento diagnóstico, tratamentos associados e volume do tumor. Para cada variável foi realizado teste de significância, que indicou se a variável em questão contribuiu ou não para a má evolução. O teste utilizado para comparar essas curvas foi o de log rank.

Apesar de a análise das curvas ter sido elucidativa, avaliou apenas a influência isolada de cada variável e desconsiderou o efeito das demais. Para a análise global, foi realizada análise multivariada, ajustando os

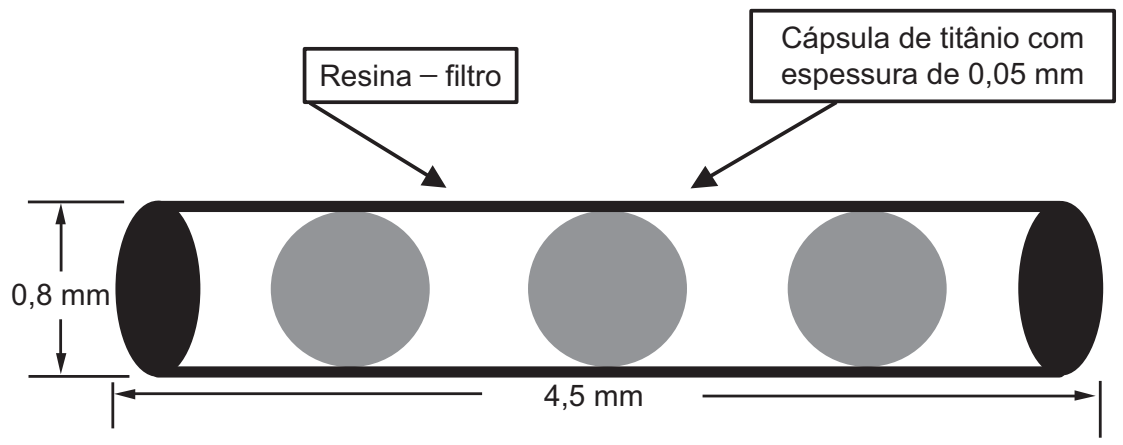

Figura 4 - Representação gráfica do ${ }^{125}$ I (IMC - 6702). 
Modelos de Regressão de Cox, que possibilitou avaliar, ao mesmo tempo, a interferência das demais variáveis.

Os modelos de Cox foram ajustados em três etapas: primeiro, considerou-se um modelo para cada variável (modelo univariado), a seguir, foi forçada a entrada de todas as variáveis (modelo completo) e, finalmente, foram selecionadas variáveis seguindo o método iterativo Stepwise Forward (modelo reduzido) ${ }^{59}$. Esse procedimento foi realizado para todos os doentes e, individualmente, para doentes com gliomas de alto grau. Não foi possível ajustar modelos para doentes com gliomas de baixo grau em virtude do número insuficiente de observações.

Em razão da possibilidade de os procedimentos de radioterapia intersticial não modificarem a evolução natural dos doentes após a sua execução, foram organizadas curvas de Kaplan-Meier ${ }^{117}$ seguindo as variáveis sexo, idade, diagnóstico, IK1, localização da lesão, procedimento diagnóstico, procedimentos associados e volume do tumor e realizada análise multivariada para avaliar a interferência dessas variáveis na sobrevida dos doentes agrupados, ajustando os Modelos de Regressão de Cox, e, individualmente, dos doentes com gliomas de alto grau, após a realização dos procedimentos de radioterapia intersticial.
O programa utilizado para a análise estatística foi o SPSS for Windows, versão 8.0 (FPFF Advanced Statistics 6.1, 1994).

\section{Resultados}

Dos 138 pacientes avaliados, 66 eram homens $(47,8 \%)$ e 72 eram mulheres (52,2\%). A média das idades foi 43,8 anos, com desvio-padrão (DP) de 18,3 anos. Os diagnósticos mais freqüentes foram glioblastoma multiforme $(36,2 \%)$, astrocitoma grau II $(18,1 \%)$, metástase (16,7\%), astrocitoma grau I (13,0\%) e astrocitoma anaplásico (12,3\%) (Tabela 2).

A média do IK1 dos doentes foi 76,2 (DP $=11,0)$ e a média do IK2 foi $26,4(\mathrm{DP}=36,8)$, considerando-se que os doentes que morreram apresentavam índice 0 . $\mathrm{O}$ tempo médio estimado entre o início da manifestação clínica da doença e o momento da radioterapia intersticial foi de 25,8 meses ( $\mathrm{DP}=24,9$ meses). O volume médio dos gliomas foi de $45,2 \mathrm{~cm}^{3}$ e o das metástases foi de 7,3 $\mathrm{cm}^{3}$ (Tabela 3 ).

\begin{tabular}{lcc}
\hline \multicolumn{3}{c}{$\begin{array}{c}\text { Tabela 2 } \\
\text { Distribuição segundo o diagnóstico dos doentes tratados com } \\
\text { radioterapia intersticial }\end{array}$} \\
\hline Diagnóstico & $\mathbf{N}$ & $\%$ \\
\hline Glioblastoma multiforme & 50 & 36,2 \\
Astrocitoma anaplásico & 17 & 12,3 \\
Astrocitoma grau I & 18 & 13,0 \\
Astrocitoma grau II & 25 & 18,1 \\
Metástase & 23 & 16,7 \\
Oligodendroglioma anaplásico & 2 & 1,4 \\
Oligoastrocitoma grau I & 1 & 0,7 \\
Oligodendroglioma & 1 & 0,7 \\
Meningioma & 1 & 0,7 \\
Total & 138 & 100,0 \\
\hline
\end{tabular}

\begin{tabular}{|c|c|c|c|c|c|c|}
\hline \multicolumn{7}{|c|}{$\begin{array}{c}\text { Tabela } 3 \\
\text { Estatísticas descritivas das variáveis estudadas }\end{array}$} \\
\hline Variáveis & Média & Mediana & Desvio-padrão & Mínimo & Máximo & $\mathbf{N}$ \\
\hline Idade (anos) & 43,82 & 45 & 18,26 & 1 & 75 & 138 \\
\hline Índice de Karnofsky inicial & 76,23 & 70 & 10,95 & 40 & 100 & 138 \\
\hline Índice de Karnofsky final & 26,43 & 0 & 36,78 & 0 & 100 & 115 \\
\hline $\begin{array}{l}\text { Tempo de evolução após a } \\
\text { radioterapia intersticial (meses) }\end{array}$ & 16,13 & 10 & 16,49 & 0 & 77 & 114 \\
\hline $\begin{array}{l}\text { Tempo de evolução desde a } \\
\text { instalação da sintomatologia (meses) }\end{array}$ & 25,76 & 19 & 24,92 & 1 & 156 & 127 \\
\hline Volume-alvo dos gliomas $\left(\mathrm{cm}^{3}\right)$ & 45,21 & 29,70 & 50,63 & 1,10 & 267,00 & 94 \\
\hline Volume-alvo das metástases $\left(\mathrm{cm}^{3}\right)$ & 7,30 & 5,80 & 6,04 & 1,35 & 22,70 & 19 \\
\hline Volume-alvo de todas as lesões $\left(\mathrm{cm}^{3}\right)$ & 38,83 & 15,60 & 48,34 & 1,10 & 267,00 & 113 \\
\hline
\end{tabular}


As lesões localizaram-se mais freqüentemente no lobo parietal $(24,6 \%)$, seguindo-se tronco encefálico $(12,3 \%)$ e lobo frontal $(10,1 \%)$ (Tabela 4$)$.

\begin{tabular}{|c|c|c|}
\hline \multicolumn{3}{|c|}{$\begin{array}{c}\text { Tabela } 4 \\
\text { Localização encefálica predominante das lesões nos } \\
\text { doentes tratados com radioterapia intersticial }\end{array}$} \\
\hline Localização encefálica & $\mathbf{N}$ & $\%$ \\
\hline Parietal & 34 & 24,6 \\
\hline Tronco encefálico, cerebelo & 17 & 12,3 \\
\hline Frontal & 14 & 10,1 \\
\hline Frontoparietal & 12 & 8,7 \\
\hline Núcleos da base, tálamo, diencéfalo & 11 & 8,0 \\
\hline Temporoparietal & 9 & 6,5 \\
\hline \multicolumn{3}{|l|}{ Temporoparietoccipital, corpo } \\
\hline caloso posterior & 8 & 5,8 \\
\hline Temporal & 7 & 5,1 \\
\hline Occipital & 7 & 5,1 \\
\hline Frontotemporoparietal & 7 & 5,1 \\
\hline \multicolumn{3}{|l|}{ Bifrontal, frontoparietal, corpo caloso } \\
\hline anterior e/ou médio & 7 & 5,1 \\
\hline Frontotemporal & 6 & 4,3 \\
\hline Temporotalamomesencéfalo pontino & 4 & 2,9 \\
\hline Temporoparietoccipitomesencefálico & 2 & 1,4 \\
\hline Petroclival & 1 & 0,7 \\
\hline Não especificado & 2 & 1,4 \\
\hline Total de doentes & 138 & 100,0 \\
\hline
\end{tabular}

O procedimento mais utilizado para a radioterapia intersticial foi a técnica de carregamento intra-operatório com ${ }^{125} \mathrm{I}(76,8 \%)$. Foi ou havia sido realizada biópsia estereotáxica em $54,3 \%$ dos casos, telerradioterapia em $45,7 \%$ e craniotomia em $39,1 \%$ (Tabela 5 ).

\begin{tabular}{|c|c|c|}
\hline \multicolumn{3}{|c|}{$\begin{array}{c}\text { Tabela } 5 \\
\text { Distribuição dos doentes segundo os procedimentos } \\
\text { diagnósticos e terapêuticos empregados }\end{array}$} \\
\hline Procedimentos diagnósticos e terapêuticos & $\mathbf{N}$ & $\%$ \\
\hline Radioterapia intersticial com ${ }^{125} \mathrm{I}$ & 106 & 76,8 \\
\hline \multicolumn{3}{|l|}{ Radioterapia intersticial com baixa } \\
\hline taxa de dose de ${ }^{192} \mathrm{Ir}$ & 23 & 16,7 \\
\hline Ressecção guiada por estereotaxia & 18 & 13,0 \\
\hline \multicolumn{3}{|l|}{ Radioterapia intersticial com alta taxa } \\
\hline de dose de ${ }^{192} \mathrm{Ir}$ & 15 & 10,9 \\
\hline Biópsia encefálica estereotáxica & 75 & 54,3 \\
\hline Telerradioterapia & 63 & 45,7 \\
\hline Craniotomia & 54 & 39,1 \\
\hline Quimioterapia & 35 & 25,4 \\
\hline Total de doentes & 138 & 100,0 \\
\hline
\end{tabular}

Foram registradas nove complicações imediatas decorrentes do tratamento: 4 casos de osteomielite, 3 casos de celulite do couro cabeludo e 2 de fístula liquórica. Procedimentos complementares foram realizados em 13 ocasiões para o tratamento das complicações ou das condições associadas aos tumores (Tabela 6).

\begin{tabular}{lc}
\hline \multicolumn{1}{c}{\begin{tabular}{c} 
Tabela 6 \\
\multicolumn{1}{c}{$\begin{array}{c}\text { Distribuição dos procedimentos cirúrgicos } \\
\text { complementares realizados }\end{array}$} \\
\hline Procedimentos complementares
\end{tabular}} \\
\hline Derivação ventrículo-peritoneal & 8 \\
Aspiração estereotáxica de cisto tumoral & 3 \\
Derivação cisto-peritoneal & 1 \\
Correção cirúrgica de fístula liquórica & 1 \\
Total de doentes & 138 \\
\hline
\end{tabular}

Com o objetivo de tornar a análise mais consistente, algumas variáveis foram recodificadas. Os diagnósticos foram reclassificados como glioma de baixo grau, glioma anaplásico, glioblastoma multiforme, metástase e meningioma (Tabela 7). A localização dos tumores foi reclassificada em quatro grupos: lobares e segmentares cerebrais, corpo caloso, núcleos da base e tronco encefálico (Tabela 8). Quanto ao método de diagnóstico, os doentes foram classificados como tendo o diagnóstico firmado por biópsia estereotáxica ou craniotomia (Tabela 9). Procedimentos terapêuticos foram reclassificados em quatro grupos: doentes tratados com radioterapia intersticial e craniotomia ou biópsia apenas; doentes tratados com radioterapia intersticial, craniotomia ou biópsia e telerradioterapia; doentes tratados com radioterapia intersticial, craniotomia ou biópsia e quimioterapia; e doentes tratados com radioterapia intersticial, craniotomia ou biópsia, telerradioterapia e quimioterapia (Tabela 10).

As variáveis quantitativas idade, IK1 e volume das lesões foram categorizadas em faixas, de acordo com a distribuição de freqüências e segundo critérios que possibilitassem compará-las com as avaliações apresentadas em outros trabalhos publicados. Os doentes foram reclassificados, segundo as faixas etárias, em três grupos: (menos de 40 anos, de 40 a 60 anos e mais de 60 anos) (Tabela 11). Os doentes foram reclassificados como tendo IK1 de até 70 ou 70 ou mais (Tabela 12). Segundo os volumes, as lesões foram reclassificadas como tendo menos de $15 \mathrm{~cm}^{3}$, de $15 \mathrm{~cm}^{3}$ a $30 \mathrm{~cm}^{3}$, mais de $30 \mathrm{~cm}^{3}$ até $60 \mathrm{~cm}^{3}$ e mais de $60 \mathrm{~cm}^{3}$. Para os casos com mais de uma lesão, considerou-se o volume médio (Tabela 13).

\begin{tabular}{|c|c|c|}
\hline \multicolumn{3}{|c|}{$\begin{array}{c}\text { Tabela } 7 \\
\text { Distribuição dos tipos de neoplasia nos doentes submetidos } \\
\text { à radioterapia intersticial }\end{array}$} \\
\hline Diagnóstico & $\mathbf{N}$ & $\%$ \\
\hline Gliomas de baixo grau & 45 & 32,6 \\
\hline Gliomas anaplásicos & 19 & 13,8 \\
\hline Glioblastoma multiforme & 50 & 36,2 \\
\hline Metástase & 23 & 16,7 \\
\hline Meningioma & 1 & 0,7 \\
\hline Total & 138 & 100,0 \\
\hline
\end{tabular}




\begin{tabular}{lcc}
\hline \multicolumn{3}{c}{ Tabela 8} \\
Distribuição das & $\begin{array}{l}\text { localizações do volume } \\
\text { lesões neoplásicas }\end{array}$ \\
\hline \multicolumn{3}{c}{ nedominante das } \\
\hline Localização da lesão no encéfalo & $\mathbf{N}$ & $\%$ \\
\hline Lobares e cerebrais segmentares & 87 & 63,0 \\
Corpo caloso & 15 & 10,9 \\
Núcleos da base & 15 & 10,9 \\
Tronco encefálico & 19 & 13,8 \\
Não classificável & 2 & 1,4 \\
Total & 138 & 100,0 \\
\hline
\end{tabular}

Tabela 9

Distribuição dos procedimentos diagnósticos empregados

\begin{tabular}{lcc}
\hline Método diagnóstico & N & $\%$ \\
\hline Biópsia & 69 & 51,9 \\
Craniotomia & 64 & 48,1 \\
Total & 133 & 100,0 \\
\hline
\end{tabular}

Obs.: 5 doentes (4 metástases e 1 meningioma) não foram classificados

\begin{tabular}{|c|c|c|}
\hline \multicolumn{3}{|c|}{$\begin{array}{c}\text { Tabela } 10 \\
\text { Distribuição dos procedimentos diagnósticos e } \\
\text { terapêticos realizados }\end{array}$} \\
\hline Métodos diagnósticos e de tratamento & $\mathbf{N}$ & $\%$ \\
\hline $\begin{array}{l}\text { Radioterapia intersticial }+ \text { craniotomia } \\
\text { ou biópsia }\end{array}$ & 64 & 48,1 \\
\hline $\begin{array}{l}\text { Radioterapia intersticial }+ \text { craniotomia } \\
\text { ou biópsia }+ \text { RT }\end{array}$ & 36 & 27,1 \\
\hline $\begin{array}{l}\text { Radioterapia intersticial }+ \text { craniotomia } \\
\text { ou biópsia }+ \text { QT }\end{array}$ & 6 & 4,5 \\
\hline $\begin{array}{l}\text { Radioterapia intersticial }+ \text { craniotomia } \\
\text { ou biópsia }+ \text { RT }+ \text { QT }\end{array}$ & 27 & 20,3 \\
\hline Total & 133 & 100,0 \\
\hline
\end{tabular}

Obs.: 5 sem classificação (4 metástases e 1 meningioma)

$R T=$ radioterapia; $Q T=$ quimioterapia

\begin{tabular}{lcc}
\hline \multicolumn{3}{c}{ Tabela 11 } \\
& Distribuição dos doentes segundo \\
a faixa etária & N & $\%$ \\
\hline Faixa etária & 50 & 36,2 \\
\hline Menos de 40 anos & 59 & 42,8 \\
De 40 a 60 anos & 29 & 21,0 \\
Mais de 60 anos & 138 & 100,0 \\
Total & & \\
\hline
\end{tabular}

\begin{tabular}{lcc}
\hline \multicolumn{3}{c}{ Tabela } \\
\multicolumn{3}{c}{$\begin{array}{c}\text { Distribuição dos doentes segundo } \\
\text { índice de Karnofsky inicial }\end{array}$} \\
\hline Índice de Karnofsky inicial & $\mathbf{N}$ & $\%$ \\
\hline Até 70 & 71 & 51,4 \\
70 ou mais & 67 & 48,6 \\
Total & 138 & 100,0 \\
\hline
\end{tabular}

Tabela 13

Distribuição dos doentes segundo o volume-alvo tumoral $\left(\mathrm{em} \mathrm{cm}^{3}\right)$

\begin{tabular}{lcc}
\hline Volume-alvo $\left(\mathrm{em} \mathrm{cm}^{3}\right)$ & $\mathbf{N}$ & $\mathbf{\%}$ \\
\hline Menos de $15 \mathrm{~cm}^{3}$ & 54 & 47,8 \\
De 15 a $30 \mathrm{~cm}^{3}$ & 12 & 10,6 \\
Mais de $30{\text { até } 60 \mathrm{~cm}^{3}}_{\text {Acima de } 60 \mathrm{~cm}^{3}}$ & 24 & 21,2 \\
Total & 23 & 20,4 \\
\hline
\end{tabular}

\section{Sobrevida dos doentes desde a instalação} da sintomatologia

Observou-se que, 1 ano após o tratamento, mais de $70 \%$ dos doentes estavam vivos e que, aos 2 anos, aproximadamente $50 \%$ dos doentes haviam sobrevivido.

Embora, aparentemente, as mulheres tenham evoluído melhor que os homens, essa diferença não foi estatisticamente significativa, ou seja, não houve influência do sexo na sobrevida dos doentes $(p=0,109)$.

As faixas etárias dos doentes estiveram altamente correlacionadas com a evolução $(p<0,001)$. Doentes com menos de 40 anos de idade apresentaram sobrevida mais prolongada que os doentes com mais idade. A probabilidade de esses doentes sobreviverem 2 anos após o início da sintomatologia é aproximadamente o dobro da dos doentes em faixas etárias acima de 40 anos, acentuando-se à medida que se prolonga o acompanhamento.

Houve relação entre o diagnóstico e a sobrevida dos doentes $(p<0,001)$. Doentes com gliomas de baixo grau ou gliomas anaplásicos apresentaram maior probabilidade de sobrevida que os doentes com glioblastoma multiforme ou metástase. Não ocorreu diferença na sobrevida de doentes com glioblastoma multiforme e metástase.

Não foram detectadas diferenças estatisticamente significativas na relação entre a localização da lesão e a sobrevida dos doentes $(p=0,415)$.

Observou-se que não houve diferença estatisticamente significativa quanto às curvas de Kaplan-Meier em relação à natureza da intervenção cirúrgica para coleta de material para exame anatomopatológico. Tanto doentes submetidos à biópsia estereotáxica como à craniotomia apresentaram sobrevidas semelhantes $(\mathrm{p}=0,331)$.

Observou-se diferença na evolução entre os doentes tratados apenas com radioterapia intersticial e aqueles tratados com radioterapia intersticial e telerradioterapia, ou com radioterapia intersticial, telerradioterapia e quimioterapia $(\mathrm{p}=0,014)$. Os doentes tratados apenas com RI apresentaram probabilidade de sobrevida maior.

Não foram observadas diferenças nas curvas de sobrevida em relação ao volume das lesões $(p=0,299)$. 
Na tabela 14 são apresentados os resumos da análise de sobrevida dos doentes desde a instalação dos sintomas, em relação a sexo, faixas etárias, diagnósticos, IK1, localização da lesão, procedimento para coleta de material para exame anatomopatológico, procedimentos realizados e volume das lesões.

\section{Modelos de Regressão de Cox}

Na tabela 15 estão apresentados os resultados dos Modelos de Regressão de Cox em três fases. Para o total de doentes, os modelos univariados retrataram o que foi verificado na análise das curvas, ou seja, a influência significativa da idade, do diagnóstico, IK1 e dos procedimentos realizados. Analisando os resultados, verificou-se que ocorreu diferença na evolução entre doentes com diagnóstico de glioblastoma multiforme e metástases em relação aos doentes com gliomas de baixo grau no modelo univariado, modelo completo e modelo reduzido da Regressão de Cox. Comparando esses resultados com os do modelo completo, verificou-se que a idade deixa de ter importância estatisticamente significativa. No modelo univariado, observou-se que doentes tratados com radioterapia intersticial apenas, ou com radioterapia intersticial e quimioterapia, apresentaram diferença quanto à sobrevida em relação aos doentes tratados com telerradioterapia ou telerradioterapia e quimioterapia. Comparando esses resultados com o do modelo completo, verificou-se que os procedimentos terapêuticos adjuvantes perderam importância e deixaram de ser estatisticamente significativos. Em relação ao sexo, observou-se que não ocorreu diferença estatisticamente significativa no modelo univariado. Entretanto, essas diferenças tornaram-se significativas no modelo completo e no modelo reduzido.

\begin{tabular}{|c|c|c|c|c|}
\hline \multicolumn{5}{|c|}{$\begin{array}{c}\text { Tabela } 14 \\
\text { Resumo da análise de sobrevida dos doentes tratados pela radioterapia intersticial desde o início da sintomatologia* }\end{array}$} \\
\hline Variáveis & $\begin{array}{c}\text { Número de casos } \\
\text { avaliados }\end{array}$ & $\begin{array}{c}\text { Sobrevida média } \\
\text { (meses) }\end{array}$ & $\begin{array}{c}\text { Intervalo de } \\
\text { confiança (95\%) }\end{array}$ & $\begin{array}{c}\text { Teste } \\
\log \text { rank }\end{array}$ \\
\hline Total & 127 & 48 & {$[35 ; 60]$} & - \\
\hline \multicolumn{5}{|l|}{ Sexo } \\
\hline Masculino & 60 & 39 & {$[23 ; 56]$} & 0,1091 \\
\hline Feminino & 67 & 51 & {$[38 ; 64]$} & \\
\hline \multicolumn{5}{|l|}{ Faixas etárias } \\
\hline Menos de 40 anos & 48 & 62 & {$[50 ; 75]$} & \\
\hline 41 a 60 anos & 53 & 34 & {$[22 ; 46]$} & 0,0000 \\
\hline Mais de 60 anos & 26 & 16 & {$[11 ; 21]$} & \\
\hline \multicolumn{5}{|l|}{ Diagnóstico } \\
\hline Glioma de baixo grau & 44 & 77 & {$[54 ; 99]$} & \\
\hline Glioma anaplásico & 17 & 50 & {$[30 ; 71]$} & 0,0000 \\
\hline Glioblastoma multiforme & 45 & 22 & {$[17 ; 27]$} & \\
\hline Metástase & 21 & 13 & {$[8 ; 17]$} & \\
\hline \multicolumn{5}{|l|}{ Índice de Karnofsky inicial } \\
\hline Até 70 & 64 & 28 & {$[21 ; 35]$} & 0,0017 \\
\hline Mais de 70 & 63 & 63 & {$[44 ; 83]$} & \\
\hline \multicolumn{5}{|l|}{ Localização da lesão no encéfalo } \\
\hline Lobos e segmentos cerebrais & 83 & 44 & {$[32 ; 56]$} & \\
\hline Corpo caloso & 13 & 42 & {$[17 ; 67]$} & 0,4147 \\
\hline Núcleos da base & 15 & 55 & {$[34 ; 75]$} & \\
\hline Tronco encefálico & 15 & 26 & {$[15 ; 36]$} & \\
\hline \multicolumn{5}{|l|}{$\begin{array}{l}\text { Procedimento para coleta de } \\
\text { material anatomopatológico }\end{array}$} \\
\hline Craniotomia & 62 & 53 & {$[34 ; 72]$} & 0,3309 \\
\hline Biópsia estereotáxica & 62 & 44 & {$[31 ; 57]$} & \\
\hline \multicolumn{5}{|l|}{ Procedimentos realizados } \\
\hline Radioterapia intersticial + craniotomia ou biópsia & 56 & 78 & {$[52 ; 104]$} & \\
\hline Radioterapia intersticial + craniotomia ou biópsia + RT & 35 & 27 & {$[20 ; 34]$} & 0,0135 \\
\hline Radioterapia intersticial + craniotomia ou biópsia + RT + QT & 27 & 35 & {$[20 ; 51]$} & \\
\hline \multicolumn{5}{|l|}{ Volume das lesões } \\
\hline Menos de $15 \mathrm{~cm}^{3}$ & 49 & 31 & {$[22 ; 40]$} & \\
\hline De $15 \mathrm{~cm}^{3}$ a $30 \mathrm{~cm}^{3}$ & 12 & 78 & {$[32 ; 124]$} & 0,2986 \\
\hline Mais de $30 \mathrm{~cm}^{3}$ até $60 \mathrm{~cm}^{3}$ & 22 & 34 & {$[22 ; 46]$} & \\
\hline Mais de $60 \mathrm{~cm}^{3}$ & 23 & 44 & {$[30 ; 58]$} & \\
\hline
\end{tabular}

$R T$ = telerradioterapia; $Q T$ = quimioterapia; *excluídos doentes com dados incertos 


\begin{tabular}{|c|c|c|c|}
\hline \multicolumn{4}{|c|}{$\begin{array}{c}\text { Tabela } 15 \\
\text { Significância (valores de } p \text { ) para as variáveis nos Modelos de Regressão de Cox dos doentes } \\
\text { avaliados desde o início da sintomatologia }\end{array}$} \\
\hline Variáveis & Modelo univariado & Modelo completo & Modelo reduzido \\
\hline Sexo & 0,1149 & 0,0580 & 0,0191 \\
\hline Idade & 0,0000 & 0,9255 & - \\
\hline \multicolumn{4}{|l|}{ Diagnóstico } \\
\hline Astrocitoma anaplásico / glioma de baixo grau & 0,2419 & 0,2587 & 0,1898 \\
\hline Glioblastoma multiforme / glioma de baixo grau & 0,0000 & 0,0094 & 0,0003 \\
\hline Metástase / glioma baixo de grau & 0,0000 & 0,0000 & 0,0000 \\
\hline Índice de Karnofsky inicial & 0,0023 & 0,0000 & 0,0000 \\
\hline \multicolumn{4}{|l|}{ Localização da lesão no encéfalo } \\
\hline Corpo caloso / lobos ou segmentos cerebrais & 0,8766 & 0,5227 & - \\
\hline Núcleos da base / lobos ou segmentos cerebrais & 0,1498 & 0,6178 & - \\
\hline Tronco encefálico / lobos ou segmentos cerebrais & 0,5484 & 0,1548 & - \\
\hline \multicolumn{4}{|l|}{$\begin{array}{l}\text { Procedimento para coleta de material } \\
\text { anatomopatológico }\end{array}$} \\
\hline Craniotomia / biópsia & 0,3369 & 0,0631 & - \\
\hline \multicolumn{4}{|l|}{ Procedimentos terapêuticos adjuvantes } \\
\hline $\mathrm{RT} /$ sem RT e QT & 0,0077 & 0,3056 & - \\
\hline $\mathrm{RT}$ e QT / sem RT e QT & 0,0282 & 0,2544 & - \\
\hline Volume das lesões & 0,3024 & 0,7352 & - \\
\hline
\end{tabular}

$R T=$ telerradioterapia; $Q T=$ quimioterapia

\section{Sobrevida dos doentes após o tratamento com a radioterapia intersticial Curvas de Kaplan-Meier}

Observou-se que, 1 ano após o tratamento, a probabilidade de o doente sobreviver foi pouco superior a $50 \%$, aos 2 anos foi de, aproximadamente, $35 \%$ e, após 2 anos, reduziu-se para menos de $30 \%$.

Embora, aparentemente, as mulheres tenham evoluído melhor que os homens, o teste estatístico não indicou influência do sexo no período de sobrevida $(\mathrm{p}=0,128)$.

As faixas etárias dos doentes estiveram altamente correlacionadas com a sobrevida $(p<0,001)$. Doentes com menos de 40 anos evoluíram melhor que os doentes mais idosos. A probabilidade de esses doentes sobreviverem 2 anos após o tratamento foi, aproximadamente, o dobro da dos doentes na faixa dos 40 aos 60 anos (60\% versus $30 \%)$.

A sobrevida após o tratamento foi influenciada pelo diagnóstico $(p=0,001)$. Doentes com gliomas de baixo grau ou anaplásicos apresentaram probabilidade maior de sobrevida, após o tratamento, que os doentes com glioblastoma multiforme ou metástases. A evolução, após o tratamento dos doentes com gliomas de baixo grau, diferiu da dos doentes com gliomas anaplásicos. $\mathrm{O}$ mesmo ocorreu entre doentes com glioblastoma multiforme e metástases.

O IK1 também é essencial para prever a sobrevida $(\mathrm{p}<0,001)$. Os doentes com IK1 de até 70 apresentaram menor sobrevida após os 5 meses de acompanhamento que os com IK1 superior.
Não foram detectadas diferenças significativas quanto à sobrevida em relação à localização da lesão neoplásica $(\mathrm{p}=0,543)$.

Os doentes que se submeteram à biópsia estereotáxica para coleta de material para exame anatomopatológico apresentaram sobrevida similar àqueles submetidos à craniotomia.

Os doentes que não foram tratados com telerradioterapia e quimioterapia evoluíram melhor $(\mathrm{p}=0,005)$.

Não foi observada influência estatisticamente significativa do volume dos tumores $(\mathrm{p}=0,591)$ na sobrevida dos doentes após o tratamento.

$\mathrm{Na}$ tabela 16 são resumidos os resultados das análises da sobrevida em relação às variáveis: sexo, faixas etárias, diagnóstico, IK1, localização da lesão no encéfalo, procedimento para coleta de material para exame anatomopatológico, procedimentos realizados $\mathrm{e}$ volume das lesões.

\section{Modelos de Regressão de Cox}

A tabela 17 apresenta os resultados dos Modelos de Regressão de Cox em três fases. Para o total de doentes, os modelos univariados retrataram o que foi verificado na análise das curvas, ou seja, influência significativa da idade, diagnóstico, IK1 e procedimentos realizados. Analisando-se os valores, verificou-se que ocorreu diferença estatisticamente significativa na sobrevida dos doentes com diagnóstico de glioblastoma multiforme ou metástase e gliomas de baixo grau, mas não entre doentes com gliomas 


\begin{tabular}{|c|c|c|c|c|}
\hline \multicolumn{5}{|c|}{$\begin{array}{c}\text { Tabela } 16 \\
\text { Resumo das análises de sobrevida após a radioterapia intersticial* }\end{array}$} \\
\hline Variáveis & $\begin{array}{l}\text { Número de casos } \\
\text { avaliados }\end{array}$ & $\begin{array}{l}\text { Sobrevida média } \\
\text { (meses) }\end{array}$ & $\begin{array}{l}\text { Intervalo de confiança } \\
\qquad(95 \%)\end{array}$ & $\begin{array}{c}\text { Teste } \\
\log \text { rank }\end{array}$ \\
\hline Total & 114 & 28 & {$[22 ; 34]$} & - \\
\hline \multicolumn{5}{|l|}{ Sexo } \\
\hline Masculino & 53 & 21 & {$[14 ; 27]$} & 0,1279 \\
\hline Feminino & 61 & 31 & {$[22 ; 40]$} & \\
\hline \multicolumn{5}{|l|}{ Faixas etárias } \\
\hline Menos de 40 anos & 42 & 49 & {$[38 ; 60]$} & \\
\hline 41 a 60 anos & 48 & 16 & {$[11 ; 20]$} & 0,0000 \\
\hline Mais de 60 anos & 24 & 10 & {$[6 ; 14]$} & \\
\hline \multicolumn{5}{|l|}{ Diagnóstico } \\
\hline Glioma de baixo grau & 37 & 42 & {$[30 ; 53]$} & \\
\hline Glioma anaplásico & 16 & 34 & {$[19 ; 49]$} & 0,0005 \\
\hline Glioblastoma multiforme & 40 & 15 & {$[9 ; 20]$} & \\
\hline Metástase & 21 & 10 & {$[6 ; 14]$} & \\
\hline \multicolumn{5}{|l|}{ Índice de Karnofsky inicial } \\
\hline Até 70 & 56 & 15 & {$[10 ; 21]$} & 0,0002 \\
\hline Mais de 70 & 58 & 38 & {$[28 ; 47]$} & \\
\hline \multicolumn{5}{|l|}{ Localização da lesão no encéfalo } \\
\hline Lobos e segmentos cerebrais & 74 & 30 & {$[22 ; 38]$} & \\
\hline Corpo caloso & 12 & 16 & {$[7 ; 24]$} & \\
\hline Núcleos da base & 14 & 33 & {$[18 ; 48]$} & 0,5425 \\
\hline Tronco encefálico & 14 & 18 & {$[8 ; 28]$} & \\
\hline \multicolumn{5}{|l|}{$\begin{array}{l}\text { Procedimento para coleta de material } \\
\text { anatomopatológico }\end{array}$} \\
\hline Craniotomia & 54 & 27 & {$[20 ; 35]$} & 0,3937 \\
\hline Biópsia & 57 & 26 & {$[18 ; 35]$} & \\
\hline \multicolumn{5}{|l|}{ Procedimentos realizados } \\
\hline Radioterapia intersticial + craniotomia ou biópsia & 47 & 42 & {$[32 ; 53]$} & \\
\hline Radioterapia intersticial + craniotomia ou biópsia $+\mathrm{RT}$ & 33 & 17 & {$[10 ; 24]$} & 0,0051 \\
\hline Radioterapia intersticial + craniotomia ou biópsia $+\mathrm{RT}+\mathrm{QT}$ & 25 & 16 & {$[10 ; 22]$} & \\
\hline \multicolumn{5}{|l|}{ Volume das lesões } \\
\hline Menos de $15 \mathrm{~cm}^{3}$ & 45 & 27 & {$[17 ; 36]$} & \\
\hline De $15 \mathrm{~cm}^{3}$ a $30 \mathrm{~cm}^{3}$ & 11 & 23 & {$[16 ; 29]$} & 0,5907 \\
\hline Mais de $30 \mathrm{~cm}^{3}$ até $60 \mathrm{~cm}^{3}$ & 17 & 23 & {$[11 ; 35]$} & \\
\hline Mais de $60 \mathrm{~cm}^{3}$ & 22 & 20 & {$[13 ; 27]$} & \\
\hline
\end{tabular}

$R T$ = telerradioterapia; $Q T$ = quimioterapia; * excluídos doentes com dados incertos

anaplásicos e gliomas de baixo grau. Comparando esses resultados com os do modelo completo, verificou-se que a idade e o diagnóstico perderam importância e não mais foram significativos estatisticamente. Do mesmo modo, a localização do tumor tornou-se elemento significativo no modelo completo quando foram comparados doentes com tumor do corpo caloso com doentes com tumor lobar e segmentar cerebral. O IK1 e os tratamentos associados, tanto no modelo univariado como multivariado, mantiveram-se significativos. No modelo reduzido, o IK1 e o diagnóstico foram significativos quando se compararam doentes com metástase e com gliomas de baixo grau. Em todas as situações, o IK1 foi, entre as variáveis investigadas, o fator que melhor previu a evolução dos doentes.

\section{Gliomas de baixo grau}

Vinte e um doentes com astrocitoma de baixo grau eram do sexo feminino e 24, do masculino. As idades variaram entre 6 meses e 60 anos. A mediana das idades foi 31 anos e a média, 28 anos. Os valores do IK1 variaram de 50 a 100.

O IK2 não foi determinado em 7 casos. Nos demais, variou de 30 a 100 . Dezoito doentes haviam falecido ao final do acompanhamento. $\mathrm{O}$ volume das lesões variou de $2,5 \mathrm{~cm}^{3}$ a $183 \mathrm{~cm}^{3}$ (média $=47,5 \mathrm{~cm}^{3}$ e mediana $=15,1 \mathrm{~cm}^{3}$ ). A duração do acompanhamento nos 44 casos, em que o tempo de evolução desde o início da sintomatologia foi avaliado, variou de 3 a 156 meses. Amédia foi de 38 meses e a mediana, de 31 meses. O tempo de evolução após o tratamento variou de 1 a 78 meses. 
Tabela 17

Significância (valores de p) para as variáveis nos Modelos de Regressão de Cox após o tratamento com radioterapia intersticial

\begin{tabular}{|c|c|c|c|}
\hline Variáveis & Modelo univariado & Modelo completo & Modelo reduzido \\
\hline Sexo & 0,1709 & 0,1404 & - \\
\hline Idade & 0,0003 & 0,7950 & - \\
\hline \multicolumn{4}{|l|}{ Diagnóstico } \\
\hline Astrocitoma anaplásico / glioma de baixo grau & 0,7851 & 0,9387 & 0,7696 \\
\hline Glioblastoma multiforme / glioma de baixo grau & 0,0012 & 0,9420 & 0,1190 \\
\hline Metástase / glioma de baixo grau & 0,0086 & 0,0946 & 0 \\
\hline Índice de Karnofsky inicial & $<0,0001$ & $<0,0001$ & $<0,0001$ \\
\hline \multicolumn{4}{|l|}{ Localização da lesão no encéfalo } \\
\hline Corpo caloso / lobos ou segmentos cerebrais & 0,3003 & 0,0390 & - \\
\hline Núcleos da base / lobos ou segmentos cerebrais & 0,4128 & 0,5733 & - \\
\hline Tronco encefálico / lobos ou segmentos cerebrais & 0,6475 & 0,2305 & - \\
\hline \multicolumn{4}{|l|}{$\begin{array}{l}\text { Procedimento para coleta de material } \\
\text { anatomopatológico }\end{array}$} \\
\hline Craniotomia / biópsia & 0,3943 & 0,0680 & - \\
\hline \multicolumn{4}{|l|}{ Procedimentos terapêuticos adjuvantes } \\
\hline $\mathrm{RT} / \mathrm{sem} \mathrm{RT}$ e QT & 0,0017 & 0,0580 & - \\
\hline RT e QT / sem RT e QT & 0,0053 & 0,0528 & - \\
\hline Volume das lesões & 0,9124 & 0,8452 & - \\
\hline
\end{tabular}

$R T=$ telerradioterapia; $Q T=$ quimioterapia

A média foi 21,2 meses e a mediana, 14 meses. Quarenta e três doentes haviam sido submetidos à biópsia estereotáxica, 22 à craniotomia, 5 à ressecção guiada por estereotaxia, 1 à craniectomia de fossa posterior, e 1 à biópsia a céu aberto. Radioterapia intersticial foi realizada 42 vezes com ${ }^{125} \mathrm{I}$ em 39 doentes, 7 vezes com baixa taxa de dose de ${ }^{192}$ Ir e, 2 vezes, com alta taxa de dose de ${ }^{192} \mathrm{Ir}$.

Em dez doentes, foi realizada telerradioterapia encefálica; em 5, quimioterapia; em 5, derivação ventrículo-peritoneal e, em 2, drenagem estereotáxica de cisto tumoral. Agravamento pós-operatório temporário dos déficits preexistentes, quando presentes, regrediu em até 36 horas. Um doente tratado com a técnica de ${ }^{125} \mathrm{I}$ e outro com a técnica de carregamento ulterior com ${ }^{192} \mathrm{Ir}$ apresentaram, respectivamente, osteomielite de crânio e celulite de couro cabeludo, tratados com antibióticos.

Dos 18 doentes com astrocitomas grau I, 7 permanecem vivos, 9 faleceram e os dados de 2 doentes não são precisos. Entre os 25 doentes com astrocitoma grau II, 13 encontram-se vivos, 7 faleceram e os dados de acompanhamento de 5 são incompletos. O doente com oligoastrocitoma grau II faleceu e os dados de segmento do doente com oligodendroglioma são incertos.

\section{Astrocitomas anaplásicos}

Dezenove doentes apresentavam astrocitoma anaplásico; 10 eram do sexo feminino e 9, do masculino, e as idades variaram de 11 a 69 anos. A média das idades foi 40 anos e a mediana, 39,4 anos. Nove doentes apresentavam idade inferior à mediana e dez, superior. Os valores do IK1 variaram de 50 a 90 . O volume da lesão variou de $1,1 \mathrm{~cm}^{3}$ a $125,1 \mathrm{~cm}^{3}$. O volume médio foi de de $36,5 \mathrm{~cm}^{3}$ e a mediana dos volumes foi de $35,8 \mathrm{~cm}^{3}$. O IK2 foi avaliado em 16 doentes. A craniotomia convencional foi realizada em 8 doentes, craniotomia guiada por estereotaxia em 2, biópsia estereotáxica em 9 e derivação cisto-peritoneal em 1 . Foram tratados com ${ }^{125} \mathrm{I} 14$ doentes; 4 doentes com baixa taxa de dose de ${ }^{192}$ Ir e 1 doente com alta taxa de dose de ${ }^{192} \mathrm{Ir}$. A telerradioterapia do encéfalo foi realizada em 9 doentes e a quimioterapia foi realizada em 5. Agravamento temporário dos déficits preexistentes induzidos pelo procedimento, quando presentes, regrediu em todos os casos em até 36 horas. Um doente tratado com alta taxa de dose de ${ }^{192} \mathrm{Ir}$ apresentou osteomielite, outro apresentou celulite no couro cabeludo e outro, fístula liquórica. Após tratamento com antibióticos os quadros infecciosos foram controlados. A sutura da ferida cirúrgica foi o procedimento empregado para o tratamento da fístula liquórica.

Dos doentes com astrocitoma anaplásico, 7 estão vivos, 7 faleceram e os dados de acompanhamento de 3 são incertos. Um doente com o diagnóstico de oligoastrocitoma anaplásico faleceu e o outro permanece sob acompanhamento.

\section{Glioblastomas multiformes}

Trinta doentes com glioblastoma multiforme eram do sexo feminino e 20, do sexo masculino. As idades 
variaram de 17 a 75 anos. A média das idades foi 49,7 anos e a mediana, 51 anos. Vinte e dois doentes tinham idade abaixo da mediana e 28, acima. O IK1 variou de 40 a 90 .

O IK2 de 16 casos não foi avaliado. Nos demais, a duração do tempo de acompanhamento da doença neurológica variou de 5 a 60 meses (média $=18,61$ meses). A duração do acompanhamento após o tratamento variou de 1 a 60 meses (média $=12,38$ meses).

Craniotomia convencional foi realizada em 31 doentes, craniotomia guiada por estereotaxia em 5, biópsia estereotáxica em 23, biópsia encefálica guiada por ultra-som em 1, derivação cisto-peritoneal em um e aspiração estereotáxica de cisto tumoral noutro. Foram realizadas um total de 55 radioterapias intersticiais, sendo $31 \mathrm{com}^{125}$ I, 12 com baixa taxa de dose de ${ }^{192}$ Ir e 12 com alta taxa de dose de ${ }^{192} \mathrm{Ir}$. A telerradioterapia do encéfalo foi realizada em 33 doentes e a quimioterapia em 19. Agravamento temporário dos déficits preexistentes em decorrência do procedimento, quando presentes, regrediu em até 36 horas.

Neste grupo de 50 doentes, 9 permanecem sob controle ambulatorial, 31 faleceram e os dados de acompanhamento de 10 são incertos.

Não foi verificada diferença quanto à evolução entre doentes com gliomas de alto grau tratados ou não com quimioterapia (Tabelas 18 e 19).

Não foram observadas diferenças estatisticamente significativas em relação às curvas de sobrevida após o tratamento com radioterapia intersticial dos doentes com glioblastomas multiformes tratados ou não com quimioterapia desde a instalação da sintomatologia (Tabela 18).

A tabela 20 apresenta os resultados dos Modelos de Cox em três fases para a avaliação dos doentes com gliomas de alto grau desde o início da sintomatologia. Foi notada influência significativa da idade, da localização do tumor no corpo caloso em relação ao tumor localizado nos lobos ou segmentos cerebrais, da localização do tumor nos núcleos da base ou nos lobos dos segmentos cerebrais e do emprego de radioterapia em relação ao tratamento por radioterapia intersticial apenas no modelo univariado, mas não no modelo complexo. Quanto ao procedimento de coleta de material para exame anatomopatológico, foi observada uma diferença estatisticamente significativa entre doentes tratados com craniotomia em relação aos submetidos apenas à biópsia, quando o modelo completo foi considerado. O IK1, tanto no modelo univariado como no modelo completo reduzido, manteve-se significativo (Tabela 20).

A tabela 21 apresenta os resultados dos Modelos de Regressão de Cox em três fases nos doentes com gliomas de alto grau após o tratamento com radioterapia intersticial.

\section{Metástases encefálicas}

Entre os 23 doentes com metástases, 10 eram do sexo feminino e 13, do masculino. As idades variaram de 25 a 75 anos (mediana $=54$ anos e média $=56$ anos $)$. O IK2 não foi estimado em 2 casos. Nos demais, o tempo de evolução da sintomatologia variou de 1 mês a 28 meses $($ mediana $=8$ meses e média $=11,57$ meses $) . \mathrm{O}$ tempo de evolução após a radioterapia intersticial variou entre 5 dias e 270 meses (média $=10$ meses e mediana $=$ 7,6 meses). Um paciente que apresentava IK1 de 90, durante sessão de quimioterapia, apresentou parada cardíaca; outro, que apresentava IK1 igual a 90, sofreu parada respiratória e cardíaca durante exame contrastado do esôfago no quinto dia após a realização do procedimento de radioterapia intersticial. Ressecção guiada por estereotaxia foi realizada em 8 doentes, biópsia estereotáxica em 14 e derivação ventrículoperitoneal em 1. Foram tratados com ${ }^{125} \mathrm{I}$ os 23 doentes desse grupo, em que telerradioterapia do encéfalo foi realizada em 8 doentes e quimioterapia em 5 .

Das 23 metástases, 30,4\% eram do pulmão, 21,7\% eram de órgãos não determinados e $17,4 \%$, da mama.

\begin{tabular}{|c|c|c|c|c|}
\hline \multicolumn{5}{|c|}{ Distribuição da sobrevida média dos doentes com gliomas de alto grau tratados ou não com quimioterapia } \\
\hline Variáveis & $\begin{array}{c}\text { Número de casos } \\
\text { avaliados }\end{array}$ & $\begin{array}{c}\text { Sobrevida média } \\
\text { (em meses) }\end{array}$ & $\begin{array}{c}\text { Intervalo de } \\
\text { confiança }(95 \%)\end{array}$ & $\begin{array}{c}\text { Teste } \\
\log \text { rank }\end{array}$ \\
\hline Com quimioterapia & 25 & 29 & {$[17 ; 42]$} & 0,7518 \\
\hline Sem quimioterapia & 37 & 29 & {$[21 ; 37]$} & \\
\hline
\end{tabular}

\begin{tabular}{|c|c|c|c|c|}
\hline \multicolumn{5}{|c|}{$\begin{array}{c}\text { Distribuição da sobrevida média (em meses) dos doentes com glioblastoma multiforme tratados ou não com } \\
\text { quimioterapia após o procedimento de radioterapia intersticial }\end{array}$} \\
\hline Variáveis & $\begin{array}{l}\text { Número de casos } \\
\text { avaliados }\end{array}$ & $\begin{array}{l}\text { Sobrevida média } \\
\text { (em meses) }\end{array}$ & $\begin{array}{c}\text { Intervalo de } \\
\text { confiança }(95 \%)\end{array}$ & $\begin{array}{c}\text { Teste } \\
\log \text { rank }\end{array}$ \\
\hline Com quimioterapia & 20 & 22 & {$[16 ; 28]$} & 0,7763 \\
\hline Sem quimioterapia & 25 & 22 & {$[15 ; 29]$} & \\
\hline
\end{tabular}


Tabela 20

Significância (valores de p) para as variáveis nos Modelos de Regressão de Cox dos doentes com gliomas de alto grau avaliados desde o início da sintomatologia

\begin{tabular}{lccc}
\hline Variáveis & Modelo univariado & Modelo completo & Modelo reduzido \\
Sexo & 0,0146 & 0,0467 & 0,0276 \\
Idade & 0,0009 & 0,0425 & 0,0141
\end{tabular}

Diagnóstico

Glioma anaplásico / glioma de baixo grau

Glioblastoma multiforme / glioma de baixo grau

Metástase / glioma baixo grau

Índice de Karnofsky inicial

-

Localização da lesão no encéfalo

Corpo caloso / lobos e segmentos cerebrais

Núcleos da base / lobos e segmentos cerebrais

Tronco encefálico / lobos e segmentos cerebrais

Método diagnóstico

Craniotomia / biópsia

Procedimentos terapêuticos adjuvantes

$\begin{array}{lll}\text { RT / sem RT e QT } & 0,1108 & 0,1952 \\ \text { RT e QT / sem RT e QT } & 0,2265 & 0,1805 \\ \text { Volume das lesões } & 0,5611 & 0,6366\end{array}$

Volume das lesões

$\begin{array}{ll}\mathbf{0 , 0 3 1 0} & \mathbf{0 , 0 0 1 2} \\ 0,9438 & 0,3710 \\ 0,5670 & 0,7953 \\ 0,6124 & 0,7881 \\ & \\ 0,0999 & \mathbf{0 , 0 1 0 1} \\ 0,1108 & \\ 0,2265 & 0,1952 \\ 0,5611 & 0,1805 \\ & 0,6366\end{array}$

Tabela 21

Significância (valores de p) para as variáveis nos Modelos de Regressão de Cox dos doentes com gliomas de alto grau após o tratamento com radioterapia intersticial

\begin{tabular}{lcccc}
\hline Variáveis & Modelo univariado & Modelo completo & Modelo reduzido & - \\
\hline Sexo & 0,1125 & 0,0849 & 0,1144
\end{tabular}

Diagnóstico

Glioma anaplásico / glioma de baixo grau

Glioblastoma multiforme / glioma de baixo grau

Metástase / glioma de baixo grau

Índice de Karnofsky inicial

(1)

Localização da lesão no encéfalo

Corpo caloso / lobos ou segmentos cerebrais

Núcleos da base / lobos ou segmentos cerebrais

Tronco encefálico / lobos ou segmentos cerebrais

Procedimento para coleta de

material anatomopatológico

Craniotomia / biópsia $\quad 0,4708$

0,0001

0,0010

0,0081

Procedimentos terapêuticos adjuvantes

$\mathrm{RT}$ / sem RT e QT

0,0005

0,1424

$\mathbf{0 , 0 1 6 2}$

0,7554

0,7006

0,9899

RT e QT / sem RT e QT

0,0244

0,0501

Volume das lesões

0,0702

0,1138

0,5039

0,1144

0,6506

$R T=$ telerradioterapia; $Q T=$ quimioterapia

Quatro doentes permanecem vivos, 17 faleceram e os dados de acompanhamento de 2 são imprecisos.

\section{Discussão}

A radioterapia intersticial é um método que possibilita tratar lesões neoplásicas com irradiação sem comprometer expressivamente o tecido localizado nas suas vizinhanças ${ }^{139,229}$. A exposição contínua à irradiação possibilita que a recuperação do dano subletal das células não-neoplásicas seja mais satisfatória, reduz a interferência da oxigenação tecidual na eficácia da radioterapia e sincroniza as células em proliferação nas fases M e G2, tornando-as mais sensíveis aos efeitos da radiação ${ }^{18,19}$.

A execução da radioterapia intersticial deve ser fundamentada na delineação precisa do espaço 
ocupado pelos tumores e na sua localização em ambiente estereotáxico para que a construção das curvas de isodose seja apropriada ${ }^{85}$. O uso de aparelho de estereotaxia é recomendado para a realização.

Programas de computação foram desenvolvidos para reconstruir as imagens coplanares da TC, da RM e da angio-RM em condições estereotáxicas. Possibilitaram também a fusão dessas imagens com as curvas de isodose, tornando mais simples e precisos os procedimentos de radioterapia intersticial ${ }^{48}$. Em nosso meio, para a realização desta tese, foi desenvolvido um programa (MSPS) que possibilitou o uso de um computador pessoal para a reconstrução tridimensional e bidimensional das imagens nos planos axial, sagital, coronal, determinação dos volumes a serem tratados e o cálculo das isodoses para isótopos implantados no encéfalo, incluindo o ${ }^{192} \mathrm{Ir}$ e o ${ }^{125} \mathrm{I}$ em condições estereotáxicas ${ }^{1}$. A reconstrução tridimensional parece reduzir a ocorrência de complicações, pois a dosimetria baseada em estudos coplanares inclui mais tecido normal que o desejável no volume irradiado e não permite comparar detalhadamente o volume tratado com o volume do tumor ${ }^{216}$.

Muitos admitem que a dose de $10 \mathrm{cGy} / \mathrm{h}$ na margem do volume-alvo, até atingir $60 \mathrm{~Gy}$, é satisfatória para a radioterapia intersticial dos gliomas e metástases encefálicas, valor este geralmente alcançado após 20 a 30 dias de exposição. Para realizar este trabalho, a média da taxa da dose de radioterapia intersticial empregada foi $10 \mathrm{cGy} / \mathrm{h}$ na periferia da lesão, evidenciada pelo contraste durante o exame de TC, e a dose mínima aplicada na periferia do volume irradiado foi 60 Gy.

Bernstein e cols. ${ }^{24}$ empregaram dose e taxa de dose similares em casos de astrocitomas anaplásicos como forma inicial de tratamento e, nos casos de astrocitomas malignos recidivados e tumores metastáticos, dose de 70 Gy. Recomenda-se que a radioterapia intersticial seja realizada após a segunda semana do término da telerradioterapia em casos de gliomas anaplásicos ${ }^{24}$.

Os protocolos de radioterapia intersticial geralmente consideram a histologia, a definição do limite do volume-alvo (relação com o limite que capta contraste e o edema, biópsia seriada em vários trajetos), o volume das lesões, a localização dos alvos em relação aos núcleos da base, os tratos e os núcleos de nervos cranianos e outras estruturas funcionalmente fundamentais do encéfalo e a associação com cirurgias, telerradioterapia ou outros procedimentos adjuvantes ${ }^{127,149,159,174,237}$. Em virtude da conformação irregular das lesões, especialmente após as intervenções operatórias, o planejamento da radioterapia intersticial deve ser rigoroso e detalhado. Para a execução deste trabalho foi considerado como limite do alvo da radioterapia intersticial a superfície que delineia os pontos situados dez milímetros externamente à superfície que capta contraste em casos de gliomas anaplásicos ou o limite evidenciado nas imagens da estéreo-TC ou da fusão destas com as da RM em casos de gliomas de baixo grau e metástases. Protocolo semelhante foi utilizado por Bernstein e cols. ${ }^{24}$

Mais de $40 \%$ dos doentes na presente casuística apresentavam idade variando de 40 a 60 anos. Isso foi devido provavelmente ao fato de haver grande número de doentes com gliomas de baixo grau e astrocitomas anaplásicos que se manifestam nessas faixas etárias com freqüência mais elevada que em doentes mais idosos.

As condições físicas e funcionais dos doentes são parâmetros que se relacionam com o prognóstico dos doentes tratados de tumores encefálicos. Na presente casuística, o índice de Karnofsky quando da realização do procedimento foi superior a 50 . A média dos valores foi 76,23 e a mediana, 70. Foi demonstrado que a evolução dos doentes com neoplasias do sistema nervoso central, especialmente dos gliomas anaplásicos, é mais insatisfatória em doentes com idades mais avançadas ${ }^{183}$. No presente trabalho a média de idade dos doentes foi 43,82 anos e a mediana, 45 anos.

$\mathrm{Na}$ presente casuística, os volumes das lesões variaram de $1,1 \mathrm{~cm}^{3}$ a $267 \mathrm{~cm}^{3}$. Aproximadamente $50 \%$ dos doentes apresentavam lesões com mais de $15 \mathrm{~cm}^{3}$. A média dos volumes foi $38,3 \mathrm{~cm}^{3}$ e a mediana, 15,60 $\mathrm{cm}^{3}$. Esses valores são inferiores aos descritos por Bernstein e cols. ${ }^{24}$, que irradiaram volumes de $2,6 \mathrm{~cm}^{3}$ a $272,0 \mathrm{~cm}^{3}\left(\right.$ mediana $\left.=78 \mathrm{~cm}^{3}\right)$. Esses autores concluíram que o procedimento não é recomendado quando as lesões apresentam mais que cinco centímetros de diâmetro à TC, especialmente quando localizados profundamente ou em regiões de grande importância funcional. Esses dados demonstram que a radioterapia intersticial pode ser empregada para a irradiação de lesões com volumes superiores àqueles credenciados para tratamento radiocirúrgico.

A biópsia estereotáxica ou a céu aberto, guiada ou não por estereotaxia, é necessária para precisar diagnóstico das lesões expansivas intracranianas. Mesmo em doentes com forte suspeita de metástases encefálicas, o diagnóstico presuntivo, baseado apenas nos exames de imagem, pode induzir à adoção de procedimentos terapêuticos inadequados ${ }^{214}$. Foram realizadas craniotomias em $39,1 \%$ dos doentes e biópsia estereotáxica em $54,3 \%$ dos doentes da presente casuística para elucidar o diagnóstico no presente trabalho. As biópsias estereotáxicas são bastante seguras. A morbidade é inferior a $3 \%$ e a mortalidade, inferior a $1 \%$, mesmo quando o maior contingente do tumor está localizado no tronco 
encefálico, nos gânglios da base ou no tálamo ${ }^{158}$. Em menos de 3\% dos casos ocorrem sintomas devidos a hemorragias ${ }^{8,158,184,188}$. Em mais de $90 \%$ dos casos, este procedimento proporciona o diagnóstico histopatológico preciso ${ }^{9,214,215}$. Procedimentos cirúrgicos destinados ao tratamento de hidrocefalia, aspiração estereotáxica de cistos tumorais, derivação de cistos neoplásicos e correção cirúrgica de fístula liquórica foram indicados em menos de $10 \%$ dos doentes da presente casuística para melhorar suas condições neurológicas. A necessidade de procedimentos associados foi ressaltado por outros autores ${ }^{24}$.

Existe muita controvérsia a respeito do momento da indicação de procedimentos adjuvantes para o tratamento de lesões expansivas encefálicas. Telerradioterapia foi utilizada como procedimento adjuvante em $45,7 \%$ dos casos dessa casuística. A quimioterapia exerce papel importante no tratamento das lesões encefálicas metastáticas, especialmente quando múltiplas e quando a lesão primária é quimiossensível. Há controvérsias sobre sua eficácia em casos de lesões neoplásicas gliais ${ }^{188}$. Admite-se que a quimioterapia sensibilize as lesões neoplásicas do sistema nervoso à ação da irradiação ${ }^{90}$. Esse fenômeno pode constituir fator de risco para a realização de telerradioterapia, uma vez que durante sua execução há, necessariamente, irradiação do tecido encefálico situado entre a lesão neoplásica e o ponto de penetração dos feixes de irradiação na superfície craniana. Essa possibilidade é minimizada durante a realização da radioterapia intersticial, uma vez que a fonte de radioterapia localiza-se no interior da lesão. De acordo com a curva de isodose estipulada e com a natureza do isótopo relacionado, é possível que mínimo ou nenhum acometimento do tecido encefálico seja induzido.

Foram analisadas as curvas de Kaplan-Meier segundo os parâmetros sexo, faixas etárias, diagnósticos, índice de Karnofsky durante a realização da radioterapia intersticial, localização da lesão, execução ou não de craniotomia pré e pós-operatória, procedimentos adjuvantes e volume das lesões. Observou-se que, aparentemente, os indivíduos do sexo feminino evoluíram de modo mais satisfatório do que os do sexo masculino, mas essa diferença não foi estatisticamente significativa $(p=0,109)$. Observou-se também que, aos 18 meses de tratamento, para probabilidade de sobrevida dos doentes foi superior a $70 \%$ e, aos 2 anos de acompanhamento, reduziu-se a aproximadamente $50 \%$. Foi observado também que doentes com menos de 40 anos de idade apresentavam sobrevida mais prolongada que os doentes com mais idade. A probabilidade de os doentes com idades inferiores a 40 anos sobreviverem 2 anos ou mais após a apresentação da sintomatologia foi aproximadamente o dobro da dos com idades superiores. Essa diferença foi significativa $(\mathrm{p}<0,001)$ e acentuou-se à medida que se prolongou o período de acompanhamento. Houve também forte correlação entre o índice de Karnofsky, durante a execução de radioterapia intersticial, e a evolução dos doentes. Quando IK1 foi igual ou inferior a 70, a probabilidade de sobrevida reduziu-se. Esses achados coincidem com o observado por outros autores avaliando doentes com gliomas encefálicos ${ }^{188}$. Observou-se também que doentes com gliomas de baixo grau e gliomas anaplásicos apresentaram maior probabilidade de sobrevida do que os doentes com glioblastoma multiforme ou metástase $(\mathrm{p}<0,01)$. Esse citado reforça o conceito já firmado por outros autores sobre a agressividade do glioblastoma multiforme e a potencialidade de os doentes com metástase encefálica apresentarem redução da sobrevida por causa da progressão da doença sistêmica. Por distanciar-se dos objetivos do presente trabalho, a análise das razões da menor sobrevida nos doentes com metástase não foi realizada. Não foi notada diferença na curva de sobrevida entre doentes com lesões localizadas nos lobos ou nos segmentos cerebrais, no tronco encefálico ou nas regiões profundas do cérebro $(\mathrm{p}=$ 0,415 ). É possível que esse achado seja por causa de maior comprometimento funcional dos doentes com lesões localizadas no tronco encefálico e de maior dimensão das lesões nos doentes com tumor lobar ou segmentar encefálico. Não foram constatadas diferenças estatisticamente significativas entre a sobrevida dos doentes tratados previamente, ou não, com craniotomia. Esse achado, considerado isoladamente, contraria o observado por outros autores, que concluíram que craniotomia torna mais favorável a evolução dos doentes com lesões expansivas intracranianas ${ }^{154,188}$. Admite-se que a cirurgia citorredutora proporciona sobrevida mais prolongada e satisfatória que a radioterapia ou outras medidas adjuvantes ${ }^{183}$. Esses dados sugerem que a radioterapia intersticial parece beneficiar os doentes independentemente da execução dos procedimentos com finalidade terapêutica. Não foi observada relação do volume das lesões encefálicas e a probabilidade de sobrevida. Seria esperado que doentes com tumores pouco volumosos apresentassem evolução mais favorável que aqueles com lesões volumosas. As medidas adjuvantes oncoterápicas influenciaram desfavoravelmente a curva de probabilidade de sobrevida. Não houve, entretanto, diferença estatisticamente significativa no resultado da análise da probabilidade de sobrevida de doentes submetidos ou não à telerradioterapia e/ou à quimioterapia no período pós-operatório. Esses dados também não coincidem com os relatados por outros autores, que observaram que a radioterapia adjuvante melhora a 
evolução de doentes com metástases e gliomas anaplásicos ${ }^{10,148,171,191,204}$. Provavelmente, isso ocorreu em razão de ter havido, na presente casuística, número elevado de doentes com gliomas de baixo grau, condição em que, freqüentemente, medidas adjuvantes não são prescritas. Podem traduzir, também, tendência de se indicar telerradioterapia e quimioterapia em doentes com afecções neoplásicas malignas, condições que, por si, implicam pior prognóstico.

Por causa da possibilidade de interação de vários fatores na sobrevida, foi avaliada a interferência dos parâmetros idade, sexo, natureza da afecção, volume da lesão, realização ou não de craniotomia, quimioterapia ou radioterapia nos doentes segundo os modelos de regressão de Cox. Confirmando os resultados da análise das curvas de Kaplan-Meier no modelo univariado da análise da regressão de Cox, doentes tratados com radioterapia intersticial e telerradioterapia e radioterapia intersticial, telerradioterapia e quimioterapia, em relação aos tratados com radioterapia intersticial apenas e doentes com idade mais avançada, apresentaram probabilidade de sobrevida menos favorável. No modelo completo, a natureza dos procedimentos perdeu importância. No modelo completo, mas não no modelo reduzido, indivíduos do sexo feminino apresentaram probabilidade de sobrevida mais prolongada. Segundo o modelo univariado, completo e reduzido de Cox, os doentes com astrocitomas anaplásicos e gliomas de baixo grau apresentaram probabilidade de sobrevida similar, e os doentes com glioblastoma multiforme e metástases apresentaram probabilidade de sobrevida menor que os doentes com gliomas de baixo grau. Foi também marcadamente significativa a relação entre valores baixos no índice de Karnofsky e a probabilidade de sobrevida menor. Não foi observada relação entre a evolução e a localização, o volume da lesão e a sobrevida dos doentes, quer no modelo univariado quer no modelo completo.

Com a finalidade de avaliar eventuais interferências da radioterapia intersticial na evolução natural dos doentes desta casuística, foi analisada a probabilidade de sobrevida após o tratamento, de acordo com as curvas de Kaplan-Meier. Pode-se observar que, 1 ano após o tratamento, a probabilidade de o doente sobreviver foi pouco superior a $50 \%$, aos 2 anos foi de aproximadamente $35 \%$ e aos 5 anos, discretamente superior a $20 \%$. Confirmando as conclusões da análise das curvas de Kaplan-Meier relacionada à evolução total da sintomatologia, observou-se que, após o tratamento, não ocorreu também relação entre a probabilidade de sobrevida e sexo, realização de craniotomia, localização das lesões no encéfalo e volume do tumor. Doentes com idade inferior a 40 anos apresen- taram probabilidade de sobrevida mais prolongada que os com idade mais avançada. Doentes com índice de Karnofsky inferior ou igual a 70, apresentaram probabilidade de sobrevida menor que aqueles com Índice de Karnofsky superior a 70 e doentes tratados com telerradioterapia e/ou quimioterapia apresentaram menor sobrevida que doentes não tratados. A análise dos modelos de regressão de Cox, realizada para avaliar a sobrevida dos doentes após a realização da radioterapia intersticial, confirmou também muitos dos resultados do estudo em relação à evolução desde o início da sintomatologia. A interferência da idade e dos baixos valores do índice de Karnofsky na probabilidade de sobrevida foi significativa no modelo univariado, completo e reduzido. Houve diferença, no modelo univariado, na probabilidade de sobrevida dos doentes tratados apenas com radioterapia intersticial em relação aos tratados com quimioterapia e telerradioterapia ou apenas telerradioterapia. Não houve diferença na evolução entre doentes com astrocitomas anaplásicos e gliomas de baixo grau quanto à localização nos núcleos de base e tronco encefálico, à localização nos lobos e segmentos cerebrais, bem como quanto à realização ou não de craniotomia. Não houve inferência do volume da lesão na sobrevida. Diferindo da análise dos dados avaliados desde o início da sintomatologia, não foi observada relação entre a probabilidade de sobrevida e o sexo no modelo completo, diagnóstico de glioblastoma multiforme e gliomas de baixo grau no modelo univariado e diagnóstico de metástase e glioma de baixo grau no modelo completo. A localização no corpo caloso em relação à localização nos lobos ou segmentos cerebrais interferiu na probabilidade de sobrevida no modelo completo.

\section{Gliomas de baixo grau}

Os astrocitomas são os tumores encefálicos de origem glial mais freqüentes ${ }^{184}$. São responsáveis por aproximadamente $50 \%$ dos tumores do SNC. Os gliomas de baixo grau constituem cerca de $50 \%$ dos astrocitomas na infância e $20 \%$ a $40 \%$ dos astrocitomas nos adultos ${ }^{31}$. Correspondem aos graus I e II da classificação de Kernohan ou aos astrocitomas benignos da classificação da Organização Mundial de Saúde ${ }^{44}$. Os oligodendrogliomas representam 4\% a $7 \%$ de todos os gliomas intracranianos ${ }^{15}$ e situam-se em terceiro lugar em freqüência entre os gliomas ${ }^{58}$. Avaliados em conjunto, não há predominância sexual para sua ocorrência ${ }^{179}$. Os astrocitomas cerebelares representam $5 \%$ de todos os gliomas e $15 \%$ dos tumores cerebrais na infância. Nos hemisférios cerebrais, manifestam-se em doentes com média de idade de $31,5 \operatorname{anos}^{65}$. Os astrocitomas não-pilocíticos 
(astrocitomas de baixo grau propriamente ditos) compreendem a maioria dos tumores de baixo grau nos adultos e ocupam o segundo lugar em freqüência entre os tumores encefálicos primitivos. Na presente casuística, houve discreto predomínio dos indivíduos do sexo masculino (53,3\%), com média de idade de 28 anos e mediana de 31 anos, o que está de acordo com os dados de outros autores, que observaram que esses tumores ocorrem com maior freqüência em doentes do sexo masculino e com idade variando de 30 a $50 \operatorname{anos}^{144,183}$. Há outro pico de ocorrência na faixa etária de 6 a $12 \operatorname{anos}^{58}$. A média de sobrevida dos doentes adultos com astrocitoma grau II é de 46 meses. Apenas 24\% sobrevive mais que cinco anos ${ }^{183}$. Segundo Salcman ${ }^{183}$, o astrocitoma gemistocítico constitui uma outra entidade diferente da do astrocitoma de baixo grau, uma vez que ocorre em doentes com idades mais avançadas e apresenta mais agressividade, pois a sobrevida dos que dela padecem é mais curta. Apresentam comportamento semelhante aos astrocitomas anaplásicos. Na presente casuística, outros gliomas, como os gangliogliomas e os tumores neuroepiteliais primitivos, não foram incluídos.

Existem muitas controvérsias quanto às condutas $\mathrm{e}$ o momento das intervenções em doentes que apresentam gliomas de baixo grau. A sobrevida é prolongada mesmo sem terapia. Há demonstrações de que o tratamento do tumor deve ser implantado no momento da apresentação das primeiras manifestações clínicas, ou após a confirmação do diagnóstico histopatológico, ou no momento em que se constata aumento do volume ou modificação do aspecto da lesão. Muitos doentes mantêm o quadro estável durante muitos anos sem a adoção das medidas radicais ${ }^{154}$. A atitude conservadora, entretanto, parece não ser a melhor opção para muitos casos. A biologia e a história natural dos gliomas de baixo grau são variáveis importantes que devem ser consideradas quando da decisão sobre o momento da modalidade terapêutica. Admite-se que as intervenções devam ser realizadas quando houver sinais evidentes de que a afecção gera anormalidades neurológicas. Quando o comportamento do tumor é agressivo, o tratamento cirúrgico, radioterápico ou quimioterápico são recomendados para prolongar a vida e melhorar a qualidade de vida dos doentes. Quando a lesão não pode ser ressecada, a biópsia estereotáxica deve ser utilizada com finalidade diagnóstica. O período médio de sobrevida pós-operatório é de 11,9 anos para doentes com astrocitoma pilocítico, quando a ressecção é completa, $85 \%$ dos doentes sobrevivem mais de 5 anos e 79\% mais de 10 anos $^{183}$. Quando a ressecção parcial é complementada com telerradioterapia, a sobrevida em 10 anos é de $74 \%$ e, em 20 anos, de $41 \%$. Em casos de astrocitomas não-pilocíticos, é possível que ocorra melhora da qualidade de vida e prolongamento da sobrevida quando são realizadas ressecções antes mesmo da instalação dos sintomas ${ }^{20}$. $\mathrm{O}$ tratamento, portanto, deve ser agressivo durante a apresentação dos sintomas iniciais, uma vez que há tendência à malignização ${ }^{183}$. Salcman ${ }^{188}$ propõe ressecção macroscópica completa ou biópsia e ressecção parcial seguida de irradiação como primeiras intervenções e radioterapia intersticial ou quimioterapia quando houver recorrência. O objetivo da cirurgia é a redução do volume do tumor, sem comprometimento da função ${ }^{134}$. Quando as lesões são localizadas no hemisfério dominante, ao redor da fissura de Sylvius ou nas proximidades do córtex rolândico e das áreas da linguagem ou estruturas envolvidas no controle motor ou sensorial, ou quando há infiltração subcortical, o mapeamento funcional e o mapeamento anatômico intraoperatório com ultra-som, estereotaxia ou neuronavegação são necessários para a identificação e a preservação de estruturas funcionalmente importantes ${ }^{92,119}$. A ressecção radical não é recomendada em casos de lesão difusa ou que envolva estruturas da linha média, em doentes com baixo grau funcional no índice de Karnofsky ou quando afecções clínicas contra-indicam a realização de craniotomia.

O prognóstico depende da idade, da localização das lesões, das condições gerais e das terapias anteriores a que foram submetidos os doentes ${ }^{84,183}$. Há evidências de que a sobrevida relaciona-se com a magnitude da operação. Na casuística de Laws e cols. ${ }^{134}$, $32 \%$ dos doentes submetidos à biópsia apenas, $44 \%$ dos doentes submetidos à ressecção parcial e $61 \%$ dos doentes que sofreram ressecção total, respectivamente, sobreviveram mais de 5 anos. Na casuística de Mahaley e cols. ${ }^{141}, 52 \%$ dos doentes sobreviveram mais que 5 anos após ressecção completa. $\mathrm{O}$ mesmo ocorreu em $23 \%$ dos casos de doentes submetidos à biópsia e em $27 \%$ dos doentes submetidos à ressecção parcial ${ }^{183}$. Quando as lesões são detectadas incidentalmente ou são identificadas durante a investigação de causas de convulsões, a biópsia estereotáxica e o acompanhamento clínico e com exames de imagem são recomendados. Havendo evidências de progressão da lesão, ou agravamento do estado neurológico, a exérese da lesão deve ser realizada. Idade inferior a 40 anos associase a prognóstico favorável ${ }^{144}$.

Há controvérsias sobre o emprego da telerradioterapia convencional nesses doentes. Apesar de a telerradioterapia melhorar a evolução de doentes com gliomas malignos ${ }^{223}$, o mesmo ainda não foi demonstrado em doentes com astrocitomas de baixo grau ${ }^{164,198}$. Parece lógica a indicação do tratamento radioterápico após ressecções parciais, quando há constatação de recidiva e quando há modificação do padrão celular. 
Quando o comportamento é agressivo e os doentes têm menos de 40 anos, a radioterapia é benéfica. Segundo Salcman ${ }^{183}$, a sobrevida dos doentes após a ressecção parcial é da ordem de $13 \%$ a $34 \%$ e se eleva para $40 \%$ a $50 \%$ em 5 anos, quando é realizada radioterapia durante o período pós-operatório. A radioterapia é também indicada quando a lesão é inacessível.

A precisa delineação das curvas de isodose, a alta dose e a baixa taxa de energia ${ }^{156}$ tornam a radioterapia intersticial mais eficaz que a telerradioterapia fracionada, especialmente quando o glioma é circunscrito e localizado no hipotálamo, tálamo, núcleos da base, trato e quiasma óptico e no tronco encefálico ${ }^{68}$. A radioterapia intersticial deve ser realizada preferentemente com implantes temporários e com doses médias de $10 \mathrm{cGy} / \mathrm{h}$ na margem da lesão, tal como executado durante a realização do presente trabalho. Segundo Salcman ${ }^{183}$, o desempenho funcional insatisfatório dos doentes de acordo com o índice de Karnofsky implica prognóstico desfavorável. A sobrevida em 5 anos de doentes com índice de Karnofsky inferior a 70 foi de $17,7 \%$ e elevou-se para 42,6\% em doentes com índice de Karnofsky superior a 70 na casuística de McCormarck e cols. ${ }^{144}$. Segundo Ostertag e Kreth ${ }^{157}$, de 251 doentes tratados de astrocitoma grau II com diâmetro inferior a $4 \mathrm{~cm}$ e índice de Karnofsky superior a 70, a radioterapia intersticial resultou em sobrevida de $65 \%$ dos doentes em 5 anos. O índice de Karnofsky variou de 50 a 70 em 51,1\% dos doentes da presente casuística. Apesar desse aspecto, a média de sobrevida dos doentes foi 38 meses e a mediana, 31 meses, a duração média do acompanhamento pós-operatório foi 21,2 meses e a mediana, 14 meses. Analisando a curva de KaplanMeier, pode-se afirmar que a probabilidade de sobrevida em 60 meses foi superior a $50 \%$. Este achado foi semelhante ao das casuísticas combinando astrocitomas comuns e oligoastrocitomas, em que a sobrevida em 5 anos foi $51 \%{ }^{198}$, e foi superior ao de outros autores, que observaram que apenas $24 \%$ a $45 \%$ dos doentes sobreviveram 5 anos, quando a cirurgia e a radioterapia foram aplicadas $^{115,145}$, e sugere que a radioterapia intersticial proporciona prolongamento da sobrevida nos doentes com lesões residuais, lesões recidivadas ou quando a biópsia é a única intervenção possível. É provável que a idade seja a variável que isoladamente mais se relacione com o prognóstico desses doentes ${ }^{115}$. A sobrevida dos doentes com menos de 40 anos foi de 56 meses, ao passo que a de doentes com mais de 40 anos foi de apenas 30,5 meses. Cumpre salientar que aproximadamente um quinto dos doentes da presente casuística apresentava mais que 40 anos de idade. Obviamente, a idade não deve ser considerada como único fator envolvido no prognóstico desses doentes, uma vez que a localização parece também ter algum significado. Astrocitomas de tronco encefálico costumam apresentar prognóstico pior ${ }^{183}$. Influencia também a sobrevida dos doentes, a malignização das lesões ${ }^{144}$. Características radiológicas, histológicas e doses de radioterapia interferem na evolução, mas não foram avaliados durante a realização do presente estudo ${ }^{183}$. Alguns trabalhos demonstraram que a radioterapia intersticial em gliomas de baixo grau, incluindo o astrocitoma, o oligodendroglioma e o oligoastrocitoma não proporciona resultados diferentes dos da telerradioterapia ou de outras modalidades de tratamento ${ }^{25,70,164,210}$.

Quando há recidiva e progressão do tumor, o tratamento quimioterápico pode ser indicado. Se a quimioterapia é ineficaz, a radioterapia deve ser indicada em doentes com mais de 3 anos de idade ${ }^{108}$.

O tratamento dos oligodendrogliomas é também matéria controversa. Alguns autores observaram bons resultados com o tratamento cirúrgico ${ }^{134,205}$, enquanto outros não ${ }^{183}$. A cirurgia é indicada quando os tumores estão localizados em regiões acessíveis, em doente não idoso e com índice de Karnofsky elevado ${ }^{193,203}$. É também controversa a aplicação de radioterapia ${ }^{198}$ ou de radiocirurgia ${ }^{183}$ nesses casos. Apenas um doente da presente casuística apresentava oligodendroglioma e outro, oligoastrocitoma.

\section{Gliomas anaplásicos}

Os astrocitomas anaplásicos e o glioblastoma multiforme são os tumores encefálicos primários mais freqüentes no adulto. Na população pediátrica, a ocorrência de astrocitomas anaplásicos é também elevada quando se consideram apenas as lesões hemisféricas ${ }^{158}$. Na Inglaterra, o glioblastoma multiforme é diagnosticado em 7,53/100.000 habitantes/ano. O pico de ocorrência ocorre entre 50 e $59 \operatorname{anos}^{16}$. Na Suécia, no período entre 1958 e 1975, a maior prevalência foi de 4,2/100.000 habitantes/ano ${ }^{189}$. Nos Estados Unidos, $27,7 \%$ dos tumores do SNC são constituídos pelo glioblastoma multiforme e $26,6 \%$ são constituídos pelos astrocitomas ${ }^{141}$. O glioblastoma multiforme representa $20 \%$ dos tumores primários do SNC nos indivíduos com idade inferior a 14 anos. Embora os gliomas malignos encefálicos constituam aproximadamente apenas $2 \%$ de todas as neoplasias malignas, o interesse pelo seu estudo deve-se à intensa incapacidade e à elevada mortalidade decorrentes de sua ocorrência. 
A incidência dos gliomas anaplásicos varia de acordo com a idade. São malignos $34 \%$ e $85 \%$ dos astrocitomas diagnosticados em doentes com 30 a 34 anos de idade e após os 60 anos de idade, respectivamente ${ }^{218}$. A prevalência do glioblastoma multiforme e dos astrocitomas cresce de 0,2 a 0,5/100.000 habitantes nos indivíduos com idade inferior a 14 anos, para 4,5 a 1,7/100.000 habitantes nos indivíduos com mais de 45 anos de idade ${ }^{83}$. Há evidências de que o glioblastoma multiforme e o astrocitoma anaplásico sejam mais freqüentes nos indivíduos do sexo masculino e de cor branca ${ }^{155,218}$. Na presente casuística, entretanto, o glioblastoma multiforme e os astrocitomas anaplásicos predominaram no sexo feminino. A mediana das idades dos doentes da presente casuística foi 53,24 anos, o que coincide com a maior prevalência desse tipo de lesão em indivíduos com idade superior a 40 anos $^{188}$.

Menos de $20 \%$ dos doentes com glioblastoma multiforme apresentam história com duração inferior a 1 mês. Somente $10 \%$ apresentam sintomas com duração superior a 1 ano $^{178}$. Na presente casuística, a duração da sintomatologia variou de 5 a 60 meses. O tempo de existência dos sinais e dos sintomas é importante fator prognóstico. História de crise convulsiva superior a 18 meses ou ocorrência de outros sintomas com duração superior a 6 meses implicam prognóstico favorável ${ }^{178,225}$. Os gliomas de alto grau são tumores muito agressivos. A mortalidade é de, aproximadamente, $90 \%$ em 18 meses $^{178}$.

Não há consenso sobre as estratégias mais apropriadas para o tratamento dos gliomas anaplásicos. Cirurgia, radioterapia e quimioterapia continuam sendo os procedimentos mais indicados para tratá-los. Entretanto, apenas 5\% dos doentes com astrocitomas anaplásicos sobrevivem 2 anos ou mais após a execução dos procedimentos convencionais ${ }^{161,220}$. Novas tecnologias possibilitaram a realização de procedimentos operatórios e terapias adjuvantes com mais segurança. Incluem-se entre elas a neuronavegação, a radioterapia mais bem programada e o uso de quimioterápicos mais efetivos. A cirurgia guiada por estereotaxia ou neuronavegação é mais apropriada que a guiada pelo ultra-som intra-operatório, especialmente quando o objetivo é a localização de pequenos tumores em regiões anatomicamente críticas ${ }^{215}$. O mapeamento eletrofisiológico intra-operatório é mais sensível e específico para definir áreas funcionalmente importantes que as imagens da $\mathrm{RM}$ e da $\mathrm{TC}^{26}$. Reoperações devem ser consideradas quando houver evidências de que a remoção do tumor recidivado possa melhorar o desempenho funcional dos doentes ${ }^{184}$. A localização da lesão é o principal determinante das dificuldades e das limitações para o tratamento cirúrgico. Muitos estudos indicam que a simples ressecção do tumor não aumenta a sobrevida; outros sugerem que essa medida o faz ${ }^{118}$. Jelsma e Bucy ${ }^{114}$ observaram que a sobrevida dos doentes tratados com descompressão externa ou biópsia era inferior a dos tratados com ressecção radical do tumor. Esse achado foi confirmado por Chang e cols. ${ }^{47}$ ao avaliarem 554 doentes com gliomas anaplásicos. Foi constatada relação entre o montante da área que capta contraste durante o período pós-operatório e a duração da sobrevida ${ }^{7,235}$. Nelson e cols. ${ }^{150}$ analisaram os prontuários de 94 casos de astrocitomas anaplásicos e concluíram que os doentes submetidos à ressecção apresentaram sobrevida mediana mais prolongada que os submetidos apenas à biópsia, $1 \mathrm{e}$ 3 anos após o tratamento. Na presente casuística apenas dez doentes haviam sido submetidos à ressecção cirúrgica.

Admite-se que o controle local do crescimento das neoplasias malignas talvez não seja possível porque a doença encefálica é mais difusa do que a TC com contraste sugere. $\mathrm{O}$ tratamento radioterápico é considerado o método que isoladamente atua de modo mais eficaz no tratamento dos astrocitomas anaplásicos ${ }^{4,158,184,225}$. Em casos de tumores do tronco encefálico, núcleos de base e tálamo, a telerradioterapia proporciona resultados comparáveis aos das cirurgias radicais ${ }^{55}$. Admite-se que adultos com astrocitoma grau III ou IV devam ser tratados com telerradioterapia e, eventualmente, com telerradioterapia complementar de reforço ou radioterapia intersticial. Esses procedimentos prolongam a sobrevida de doentes com astrocitomas anaplásicos supratentoriais, segundo estudos retrospec$\operatorname{tivos}^{33,38,81,126,162,166,181,182,185,186,200,213,219,224,226,227,228}$ e prospectivos multicêntricos recentes ${ }^{223,225}$. Nos doentes que se submetem à excisão radical dos astrocitomas malignos, a média de sobrevida é de 4 meses; o tempo de sobrevida aumenta para 9,25 meses naqueles tratados com telerradioterapia após a ressecção ${ }^{184}$. Quando o tumor aumenta de volume durante o processo de irradiação, o prognóstico é $\mathrm{mau}^{235}$.

Nenhum estudo documentou inequivocamente a potencialidade do benefício proporcionado pela radioterapia intersticial como forma de tratamento inicial nesses $\operatorname{casos}^{72,77}$. Cerca de $30 \%$ dos doentes com gliomas anaplásicos são candidatos à radioterapia intersticial como forma inicial de tratamento. Apenas $50 \%$ dos doentes candidatos à radioterapia intersticial como intervenção inicial mantêm-se candidatos a tal procedimento após a recidiva, pois, muitas vezes, com o passar do tempo, os tumores hemisféricos passam a acometer o hemisfério contralateral ou tornam-se 
multicêntricos. A média de sobrevida dos doentes com astrocitomas anaplásicos tratados com radioterapia intersticial por Leibel e cols. ${ }^{136}$ foi de 81 semanas e a mediana de sobrevida, 44 semanas. Na presente casuística, a sobrevida dos doentes variou de 8 a 96 meses, sendo a mediana 31 meses e a média 20,5 meses; valores portanto superiores aos dos doentes tratados com cirurgia e telerradioterapia por outros autores ${ }^{184} \mathrm{e}$ similares ou superiores aos de outros autores que empregaram a radioterapia intersticial como forma de tratamento ${ }^{24,136}$. A sobrevida mediana de 12 semanas em doentes que não tenham extensão da lesão além da linha média associa-se a resultados mais favoráveis. A radioterapia intersticial prolonga também a sobrevida de doentes tratados com telerradioterapia ${ }^{49,50,51}$. Cinco doentes da presente casuística submeteram-se a tratamento por quimioterapia sem que houvesse melhora da curva de sobrevida.

Em $20 \%$ a $40 \%$ dos doentes tratados com radioterapia intersticial com ${ }^{125} \mathrm{I}$ ocorre radionecrose que requer cirurgia para remoção do tecido desvitalizado para melhorar a qualidade de vida e a duração da sobrevida ${ }^{90}$. A indicação de reoperação em doentes tratados com radioterapia intersticial é muito controversa. A avaliação da atividade metabólica talvez possa prever o resultado de reintervenção ${ }^{220}$. Walker e cols. ${ }^{226}$ e Gutin e cols. ${ }^{88}$ indicam a segunda cirurgia quando há agravamento das condições clínicas. Nova craniotomia para citorredução foi necessária em 30,4\% e terceira craniotomia em $12 \%$ dos doentes submetidos à radioterapia intersticial na casuística por Bernstein e cols. ${ }^{24}$. Segundo esses autores, reoperação foi necessária em $20,4 \%$ dos doentes tratados com radioterapia intersticial como procedimento inicial e em $27,8 \%$ dos doentes tratados de doença recidivada. Células viáveis podem ser identificadas no tecido coletado da área irradiada durante a segunda operação. Na presente casuística, 6 $(31,5 \%)$ dos 19 doentes com astrocitomas anaplásicos foram submetidos à craniotomia para remoção de lesão expansiva no transcorrer do período pós-operatório. Procedimentos adicionais podem também ser necessários. Entre eles, incluem-se a drenagem de cistos sintomáticos ${ }^{24}$, tal como ocorreu em 1 doente da presente casuística.

Em razão da natureza infiltrativa desses tumores, a ressecção completa não é possível. A telerradioterapia é geralmente prescrita para tais casos. Alguns estudos demonstraram que a irradiação, analisada como variável independente, aumenta a sobrevida dos doentes com glioblastoma multiforme ${ }^{55,60,76,107,113,114,151,178,196}$. Roth e Elvidge ${ }^{178}$ não observaram diferença quanto à sobrevida entre os doentes irradiados e aqueles submetidos a ressecções parciais ou totais. A sobrevida média dos doentes com glioblastoma multiforme após cirurgias convencionais e radioterapia foi de 37 semanas e significativamente menor nos casos em que a idade foi superior a $60 \operatorname{anos}^{158,184,225}$. A recidiva ocorre em 58\% dos doentes 6 meses após a ressecção isolada e em $28 \%$ dos doentes tratados com telerradioterapia pósoperatória $^{49}$. Newell e cols. ${ }^{152}$ observaram que a ressecção subtotal do tumor, seguida de irradiação com $3.000 \mathrm{cGy}$ de todo encéfalo, durante dez dias, resultou em sobrevida mediana de 44 semanas, enquanto a ressecção radical resultou em sobrevida de 15 semanas. Isso sugere que a telerradioterapia pós-operatória prolonga o período de sobrevida ${ }^{178}$. Utilizando análise de regressão, Weir ${ }^{230}$ observou que a irradiação melhorou significativamente a sobrevida. Hitchcock e Sato ${ }^{107}$ observaram que a sobrevida dos doentes submetidos à ressecção foi similar a dos doentes tratados apenas com descompressão externa e irradiação pós-operatória. Entretanto, Taveras e cols. ${ }^{213}$ observaram que, a longo prazo, a radioterapia pouco beneficiou doentes submetidos à biópsia ou à ressecção das lesões. Por outro lado, alguns trabalhos demonstraram que a cirurgia não modifica a evolução de doentes tratados com telerradioterapia. Scanlon e Taylor ${ }^{195}$ não notaram diferença quanto à sobrevida entre doentes submetidos à biópsia ou à ressecção das lesões e radioterapia. Coffey e cols. ${ }^{55}$ concluíram que a cirurgia citorredutora não prolongou a sobrevida de doentes tratados com telerradioterapia. Kinsella e cols. ${ }^{121}$ observaram que a cirurgia citorredutora não modificou os resultados finais; $94 \%$ dos seus doentes haviam completado o curso de radioterapia superfracionado.

No presente trabalho, observou-se que a média de sobrevida foi de 22 meses e a mediana, 18,4 meses, valores semelhantes aos apresentados por outros autores. Alguns pesquisadores ${ }^{85,86,88,89,90,91}$ observaram que a administração de quimioterápicos com finalidade sensibilizadora durante a execução da radioterapia intersticial prolonga de modo estatisticamente significativo a sobrevida dos doentes. Entretanto, na presente casuística essa intervenção não modificou a sobrevida. É possível que critérios de seleção e técnicas diferentes de execução do procedimento de radioterapia intersticial justifiquem a discrepância em relação aos resultados dos autores norte-americanos. Trabalho realizado avaliando o resultado da biópsia estereotáxica, seguida de radioterapia intersticial e telerradioterapia, revelou que os resultados foram piores quando os tumores não foram ressecados e o volume foi superior a $20 \mathrm{~cm}^{3} .58$

As drogas sensibilizadoras parecem melhorar a eficácia do tratamento radioterápico ${ }^{31,90}$. $\mathrm{O}$ efeito da radioterapia intersticial é mais expressivo quando associado à hipertermia ${ }^{175,184,187} \mathrm{e}$ à quimioterapia com nitrosuréia ${ }^{187}$. A radionecrose é rara em doentes com 
glioblastoma multiforme após o tratamento com telerradioterapia na dose de até $60 \mathrm{~Gy}^{30}$. Os doentes tratados com telerradioterapia (50 Gy) apresentam alta freqüência de recidiva e os tratados com radioterapia intersticial, alta freqüência de radionecrose, menor celularidade, pleomorfismo celular, hiperplasia celular e índice mitótico mais baixos. Esses achados, possivelmente, são relacionados à maior mortalidade celular decorrente da dose elevada de irradiação. Outros estudos sobre os efeitos da radioterapia em animais substanciam as vantagens da radioterapia intersticial ${ }^{23}$.

A administração da nitrosuréia melhora o resultado do tratamento dos gliomas malignos. Walker e cols. ${ }^{223}$ concluíram que a telerradioterapia, a quimioterapia com 1,3-bis (2-cloroetil)-1-nitrosuréia ou a combinação destes procedimentos foram mais eficazes que as cirurgias apenas. Houve correlação negativa entre biópsia e sobrevida e melhora da qualidade de vida. A cirurgia visando à ampla ressecção das lesões, associada a radioterapia convencional na dose de 60 cGy na lesão, quimioterapia e radioterapia intersticial, amplia de 24 para 36 meses a sobrevida dos doentes com glioblastoma multiforme. A média de sobrevida de doentes com glioblastoma multiforme após a excisão cirúrgica, irradiação e quimioterapia é 10 meses e reduz-se para 9,25 meses após cirurgia e radioterapia apenas $^{184}$.

Quando há recidiva 8 a 12 meses após o tratamento, a exérese cirúrgica da lesão recorrente pode ser aconselhada. Quimioterapia também deve ser considerada nesses casos. A radioterapia intersticial é a terapia isolada mais eficaz para o tratamento de doentes com lesões recorrentes ${ }^{184}$.

A radioterapia intersticial prolonga a vida, mas não cura os doentes com gliomas malignos. Células tumorais podem manter-se vivas no tecido adjacente ao tumor identificável. Pode também ocorrer resistência aparente de algumas células tumorais à radiação, o que justifica os benefícios temporários da cirurgia citorredutiva ou da telerradioterapia nos tumores anaplásicos ${ }^{119}$. Além disso, a radioterapia intersticial não controla a disseminação do tumor no compartimento liquórico.

O parâmetro isolado mais importante para o estabelecimento do prognóstico dos doentes com glioblastoma multiforme é a idade. Na maioria das casuísticas, $10 \%$ a $20 \%$ dos doentes sobrevivem durante 18 a 24 meses após o diagnóstico. Menos de $5 \%$ o faz durante 3 anos ou mais. Em crianças com gliomas de alto grau, a taxa de sobrevida de 5 anos é maior que $25 \%$, podendo $10 \%$ sobreviver 10 anos ou mais ${ }^{184}$. Os idosos apresentam sistema imunológico menos operante, o que torna os tumores mais resistentes à quimioterapia e à radioterapia. A magnitude da necrose e da anaplasia tumoral é também relacionada ao mau prognóstico.

\section{Metástases encefálicas}

As metástases encefálicas são uma das complicações neurológicas mais comuns dos tumores malignos extraneurais. Manifestaram-se em $131 \mathrm{mil}$ doentes nos Estados Unidos em 1993. São resultado da disseminação hematogênica das células de tumores situados a distância e, menos freqüentemente, de locais adjacentes como o crânio ou os tecidos moles da cabeça e do pescoço ${ }^{14}$. Estudos realizados com material de autópsia fornecem informações aproximadas sobre a ocorrência e distribuição etária das metástases encefálicas. Cerca de $12 \%$ a $35 \%$, ou seja, aproximadamente $25 \%$ dos doentes com câncer apresentam metástases intracranianas ${ }^{12,167}$. Há evidências de que a incidência das metástases intracranianas seja crescente ${ }^{46,79,168}$ devido à melhora do tratamento da condição original e, conseqüentemente, da sobrevida dos doentes com tumores, o que permite que as células metastáticas "protegidas" no SNC possam se desenvolver ${ }^{125}$. As metástases encefálicas podem manifestarse precocemente, enquanto o tumor primário ainda é oculto, sincronicamente, quando identificadas em simultaneamente ao tumor primário e, metacronicamente, quando identificadas em algum intervalo de tempo após o diagnóstico do tumor primário ${ }^{167}$. As metástases das lesões pulmonares tendem a manifestar-se precocemente, logo após o diagnóstico inicial, e as de mama, cólon e do melanoma geralmente o fazem após longos intervalos de tempo ${ }^{101}$. Cerca de $75 \%$ das metástases são metacrônicas ${ }^{10}$. Costumam ocorrer em adultos e, na presente casuística, a média das idades foi 56 anos.

A ocorrência de metástases encefálicas varia consideravelmente de acordo com o tumor ${ }^{10}$. Embora, virtualmente, todas as neoplasias malignas possam gerar metástases encefálicas, o câncer de pulmão, mama, colo e reto e o melanoma o fazem mais freqüentemente ${ }^{35,36,102,211}$. Na presente casuística, cerca de um terço dos casos de metástases era oriundo dos pulmões e um quinto, da mama, o que está de acordo com o relatado acima. O carcinoma pulmonar é a fonte mais comum de metástases encefálicas; é responsável por aproximadamente $40 \%$ a $50 \%$ dos casos nos Estados Unidos $^{10}$. O carcinoma de células escamosas causa menos metástases encefálicas que o adenocarcinoma ou o carcinoma indiferenciado ${ }^{43}$. Ocorrem metástases encefálicas em $20 \%$ a $40 \%$ dos doentes com câncer de células pequenas do pulmão. Aproximadamente $45 \%$ das metástases do câncer de pulmão são únicas e 15\%, sincrônicas ${ }^{66,171}$. Os exames de imagem freqüentemente detectam metástases pequenas e assintomáticas em $4 \%$ a $11 \%$ dos doentes candidatos a cirurgias pulmonares ${ }^{11,124}$. Isso significa que a investigação por imagem do encéfalo deve ser rotineira na fase pré-operatória 
de toracotomias para o tratamento de neoplasias pulmonares ${ }^{83}$. O carcinoma de mama é a causa mais comum de metástases encefálicas nas mulheres e a segunda causa de metástases encefálicas ${ }^{75,238}$. São as que mais amplamente se distribuem no encéfalo, podendo acometer o parênquima e a leptomeninge ${ }^{122}$. Quando acometem a dura-máter, simulam meningiomas $^{34,212}$. As metástases de neoplasias do aparelho digestivo são responsáveis por $9 \%$ dos casos ${ }^{146}$. As metástases do cólon ${ }^{209} \mathrm{e}$ do rim $^{236}$ tendem a ser isoladas e parcialmente resistentes à irradiação ${ }^{142}$. Os melanomas são tumores que mais causam metástases encefálicas. Essas são mal demarcadas, infiltram o parênquima, freqüentemente sangram e, geralmente, são múltiplas.

Em 6 dos 54 doentes da casuística de Patchell e cols. ${ }^{160}$, a biópsia ou a remoção cirúrgica das prováveis lesões metastáticas encefálicas demonstraram que estas não eram metástases. Lesões encefálicas múltiplas ou únicas, em doentes com câncer sistêmico conhecido, sugere o diagnóstico de metástases, mas o diagnóstico de certeza só é possível após o estudo histológico do material de biópsia. O tumor-fonte não é conhecido em aproximadamente $4 \%$ a $10 \%$ dos doentes que se submetem a tratamento cirúrgico de possíveis metástases encefálicas ${ }^{64,147}$.

Os procedimentos específicos para o tratamento das metástases encefálicas incluem a cirurgia, a radioterapia, a radiocirurgia e a quimioterapia. A seleção do tratamento é baseada nas condições clínicas, na qualidade do desempenho funcional, na idade e no estado neurológico dos doentes, na magnitude da doença extracraniana e intracraniana, na localização e natureza das lesões e na possibilidade do tratamento do tumor primário ${ }^{80}$. Quando o déficit neurológico é intenso e a qualidade de vida muito comprometida, as medidas não-cirúrgicas são soberanas. Quando ocorre melhora da condição neurológica após o tratamento com corticosteróides, o tratamento cirúrgico ou radioterápico deve ser reconsiderado. As lesões únicas ou em pequeno número são potencialmente tratáveis com cirurgia, radioterapia intersticial ou radiocirurgia quando não há evidência de doença sistêmica remanescente ou quando a neoplasia sistêmica foi erradicada ou tem potencialidade de ser controlada durante meses ou anos ${ }^{168}$. Quando as lesões são numerosas ou a afecção primária ou secundária é muito avançada e não controlada, a terapia focal com cirurgia ou radiocirurgia não é apropriada; a telerradioterapia e a quimioterapia paliativas devem ser indicadas nessas eventualidades.

A cirurgia é o tratamento preferido, principalmente quando a metástase é única e o câncer não é muito agressivo, tal como ocorre em aproximadamente $20 \%$ a $25 \%$ dos casos de metástases ${ }^{202}$. Os candidatos ideais para a cirurgia ocorrem em porcentagem menor ${ }^{45}$. Ocasionalmente, doentes com metástases encefálicas múltiplas podem ser beneficiados com a cirurgia, especialmente quando as lesões são radiorresistentes, cirurgicamente acessíveis e não há evidências de doença em outros locais ${ }^{28}$. Segundo Penar e Wilson ${ }^{163}$, o custo da terapia cirúrgica adicional é compensado pela paliação, porque a cirurgia melhora a função rapidamente, proporciona sobrevida prolongada e estabelece inequivocamente o diagnóstico, o que é particularmente evidente nos casos de metástases pouco vascularizadas, de pequenas dimensões e facilmente destacáveis do parênquima encefálico e a neoplasia é desconhecida. Alguns estudos prospectivos e retrospectivos demonstraram que a cirurgia melhora a sobrevida dos doentes, especialmente quando a TC pós-operatória revela que a ressecção foi radical ${ }^{3,7,52,106}$. A erradicação das metástases quando não se identificam as fontes ou quando as lesões intracranianas são isoladas prolonga a sobrevida ou resulta em cura. Quando há lesões sistêmicas disseminadas não tratáveis, a evolução é fatal em poucas semanas. Em casos em que a radioterapia é ineficaz, a cirurgia pode beneficiar doentes com metástases múltiplas desde que o estado físico seja bom e a doença sistêmica seja limitada e controlada. A cirurgia deve também ser indicada quando há ameaça à vida. Arbit e Wronski ${ }^{10}$ observaram que o tempo médio de sobrevida $(9,2$ meses), após a ressecção de metástases múltiplas em 49 doentes, foi similar ao de doentes com metástase única ( 9 meses). Esse achado foi confirmado por outros autores ${ }^{28,39}$.

A telerradioterapia, desde há muitas décadas, é empregada para o tratamento das metástases encefálicas ${ }^{57}$. É o método de escolha quando há lesões múltiplas ou metástase encefálica única inacessível em doentes com doença sistêmica disseminada, não controlada. A radioterapia proporciona sobrevida média de 4,5 meses, sobrevida de 1 ano em $10 \%$ a $15 \%$ dos doentes e ocasional sobrevida a longo prazo ${ }^{37,131}$. Segundo o Radiation Therapy Oncology Group (RTOG), 32\% dos doentes com comprometimento da motricidade e $62 \%$ dos doentes com convulsões apresentaram recuperação neurológica completa após a radioterapia e $49 \%$, melhora da função neurológica. Ocorreu melhora neurológica em $62 \%$ dos doentes tratados com biópsia e radiação e em 55\% dos casos submetidos à ressecção da metástase seguida de irradiação. Aproximadamente $40 \%$ a $45 \%$ dos doentes morrem em decorrência das metástases encefálicas após período médio de 10 a 15 semanas; menos de 50\% morrem em decorrência da doença sistêmica ${ }^{57}$. Doses elevadas isoladas causaram maior freqüência de toxicidade aguda, sobrevida menor e recorrência mais 
precoce $^{82}$. A irradiação convencional padrão com 300 cGy de todo o encéfalo durante dez sessões associouse a elevada freqüência $(>10 \%)$ de encefalopatia actínica após o primeiro ano de acompanhamento ${ }^{61}$. A necrose e a lesão neuronal generalizada podem resultar em anormalidades neurológicas localizadas ou em demência ${ }^{40}$. Patchell e cols. ${ }^{160}$ observaram que muitos doentes tratados apenas com radioterapia sem cirurgia apresentaram recorrência e faleceram em decorrência da doença neurológica. Um dos fatores que predizem o resultado da radioterapia é a histologia do tumor primário. Doentes com carcinoma de mama apresentam sobrevida mais longa que doentes com carcinoma pulmonar ${ }^{67,231}$. Doentes cujos sintomas neurológicos são mais brandos no momento em que o tratamento é iniciado melhoram mais e doentes cujos sintomas são muito expressivos melhoram menos ${ }^{10}$.

Há controvérsias quanto aos méritos da radioterapia pós-operatória ${ }^{10,147,148}$. A telerradioterapia melhora os resultados da remoção cirúrgica das metástases encefálicas únicas de carcinomas ${ }^{160}$. Arbit e Wronski ${ }^{10}$ observaram que doentes tratados com exérese cirúrgica de metástase cerebral única, seguida de irradiação de todo o encéfalo, sobreviveram mais tempo, apresentaram menos recorrências e experenciaram melhor qualidade de vida. Arbit e cols..$^{10}$ analisaram, retrospectivamente, o resultado da ressecção de metástases encefálicas de 670 doentes com idades variando de 19 a 84 anos. Destes, 621 apresentavam lesão única e 49, lesões múltiplas. A sobrevida média, pelo método Klapan-Meier, foi de 9,2 meses após a cirurgia. A idade não foi relacionada com a sobrevida. As mulheres apresentaram sobrevida média (11 meses) mais longa que os homens $(8,4$ meses). Observaram que 256 doentes $(37,2 \%)$ morreram até o sexto mês pósoperatório, sendo $5 \%$ antes do primeiro mês. A sobrevida no primeiro, segundo, terceiro e quinto ano foi $39,4 \%, 16,3 \%, 11,5 \%$ e $6 \%$, respectivamente. Os que sobreviveram mais tempo apresentavam câncer pulmonar de células não-pequenas, câncer renal, testicular e mamário, melanoma e sarcoma.

Para minimizar as complicações da telerradioterapia, a irradiação focalizada por radiocirurgia, radioterapia estereotáxica ou radioterapia intersticial foram desenvolvidas. Esses procedimentos possibilitam liberar radiação no tumor com menor agressão aos tecidos vizinhos. São particularmente apropriadas para lesões metastáticas porque estas, geralmente, são bem demarcadas e de pequenas dimensões.

Em 15\% dos casos, o parênquima encefálico é sede exclusiva das metástases e, em 10\%, apenas a metástase encefálica é identificada, e não o tumor-fonte ${ }^{147,167,197}$. Na casuística de Delattre e cols. ${ }^{62}, 49 \%$ de 288 doentes apresentavam apenas uma metástase encefálica à TC de alta resolução, $21 \%$, duas e, $13 \%$, três. Isso significa que $70 \%$ dos doentes poderiam ser candidatos à radioterapia focalizada. A radiocirurgia e a radioterapia intersticial são alternativas para o tratamento de doentes com lesões irressecáveis ou recidivadas quando as condições clínicas ou teciduais não possibilitam a realização da cirurgia ou quando há recusa para a sua realização ${ }^{21,69}$. Esses últimos procedimentos proporcionam controle local da lesão em mais de $90 \%$ dos casos.

A radiocirurgia estereotáxica é indicada para destruir as lesões intracranianas de pequenas dimensões, inacessíveis ou situadas em áreas de grande importância funcional ${ }^{137,165}$. Como a dose no encéfalo aumenta com o aumento do volume-alvo, essas técnicas devem ser limitadas a lesões pequenas e circunscritas, geralmente com menos de $3 \mathrm{~cm}$ de diâmetro ${ }^{140}$. A radiocirurgia permite o controle local da maioria das lesões e reduz o edema peritumoral e a necessidade de corticosteróides $^{74}$, mesmo de tumores radiorresistentes como o carcinoma do cólon e o melanoma ${ }^{74,206}$. Pode ser indicada para o tratamento de lesões profundas e múltiplas (até três) em uma única sessão quando a sobreposição de áreas irradiadas é mínima. Raramente há o desenvolvimento de necrose sintomática após a irradiação. Não há, entretanto, estudos controlados comparando o valor da radiocirurgia e da extirpação cirúrgica em casos de lesões encefálicas ${ }^{29}$.

A radioterapia intersticial também proporciona melhora da sobrevida e das condições neurológicas de doentes com metástases encefálicas, a custa de pequena toxicidade aguda ${ }^{21,88,104,172}$, embora alguns efeitos adversos tardios possam manifestar-se ${ }^{191}$. O resultado da radioterapia intersticial depende do tamanho e da geometria do tumor, da visualização da interface tumor-encéfalo e da radiossensibilidade. É indicada como primeira intervenção ${ }^{127}$, quando há recidiva ${ }^{103}$ ou como reforço da telerradioterapi ${ }^{172}$. A média de sobrevida foi de dez meses na presente casuística. Bernstein e cols. ${ }^{24}$ observaram sobrevida superior a 39 semanas em 3 doentes com metástases encefálicas de tumores pulmonares. Há muitos relatos de doentes com doença recorrente e controlada durante até 4 anos após a radioterapia intersticial com ${ }^{125} \mathrm{I}$. A sobrevida média dos doentes tratados com a irradiação de todo o encéfalo e com radioterapia intersticial não é maior do que a dos tratados apenas com radioterapia intersticial ou tratados apenas com irradiação de todo o encéfalo ${ }^{10}$. Há risco de radionecrose quando a radioterapia intersticial é associada à telerradioterapia. A elevada dose de irradiação pode resultar em radionecrose encefálica tardia em $40 \%$ a $50 \%$ dos doentes, geralmente durante os 6 primeiros meses que se seguem ao do tratamento ${ }^{191}$. Black ${ }^{29}$ tratou metástases encefálicas com ${ }^{125} \mathrm{I}$ na dose de 60 a 100 Gy na 
periferia das lesões visualizadas à TC com contraste. Observou-se que houve controle das lesões sem a ocorrência de expressiva radionecrose. Ainda não foi determinado se a radioterapia intersticial proporciona resultados melhores que a radiocirurgia ou a exérese cirúrgica em casos de lesões isoladas ${ }^{10}$.

Com exceção do coriocarcinoma e dos tumores germinativos $^{180}$, a quimioterapia exerce pouco efeito nas metástases encefálicas ${ }^{42}$. Há melhora em até $55 \%$ dos doentes com metástases de carcinoma de mama ${ }^{54,177}$. Os tumores quimiossensíveis podem ser resistentes à quimioterapia não apenas por causa da atuação da barreira hemato encefálica ${ }^{170}$, mas também pelo fato de muitas metástases serem mais resistentes que a lesão primária ${ }^{201}$. Não foi demonstrado se os sensibilizadores modificam os resultados funcionais e a sobrevida dos doentes.

\section{Meningiomas}

A remoção microcirúrgica é o procedimento ideal para o tratamento dos meningiomas intracranianos, pois proporciona descompressão imediata das estruturas neurais, remove o tecido-fonte do edema encefálico e resulta em cura definitiva quando a remoção é completa $^{110}$. Entretanto, proporção considerável dos doentes com meningiomas é composta por idosos, condição que se associa a numerosas afecções clínicas que contra-indicam ou aumentam o risco das intervenções operatórias convencionais. Na casuística de Maurice-Williams e Kitchen ${ }^{143}, 32 \%$ de 144 doentes com meningiomas apresentavam idade igual a 65 anos ou mais. A idade, isoladamente, não é contra-indicação para cirurgia a céu aberto; as condições clínicas e a localização das lesões constituem elementos freqüentemente mais significativos para a decisão da conduta ${ }^{12}$. As imagens da RM e da TC para a localização das estruturas adjacentes aos tumores, a embolização préoperatória para minimizar o sangramento, o conhecimento da anatomia microcirúrgica, o emprego de técnica operatória apropriada e a monitorização da atividade dos nervos cranianos possibilitaram redução da mortalidade operatória. Entretanto, déficits neurológicos transitórios ou permanentes após os procedimentos cirúrgicos ainda ocorrem freqüentemente. Para evitálos, é necessário, muitas vezes, deixar fragmentos tumorais aderidos às estruturas intracranianas. Meningiomas localizados na região parasselar ou clival, que envolvam nervos cranianos, artérias, seios venosos e haste hipofisária, raramente podem ser completamente ressecados ${ }^{2,63,192,207}$.

A radioterapia estereotáxica é um recurso útil para casos em que a ressecção foi parcial. Possibilita interromper o crescimento ou reduzir o volume do tumor. A radiocirurgia está indicada quando os tumores são pequenos ${ }^{93,123,140,208}$. A radioterapia conformacional é indicada para tratar meningiomas com grandes volumes $^{78}$.

A radioterapia intersticial parece ser mais eficiente que a radiocirurgia ${ }^{129,139}$. Kumar e cols. ${ }^{130}$ realizaram radioterapia intersticial $\mathrm{com}^{125} \mathrm{I}$ em 15 doentes com meningioma. Todos estavam vivos ao final do seguimento, que variou entre 8 e 92 meses, e não apresentaram complicações. Em 11 casos, ocorreu regressão completa do tumor e, em 4, a regressão foi parcial. Vuorinen e cols. ${ }^{22}$ implantaram, permanentemente, sementes de ${ }^{125} \mathrm{I}$ em 25 doentes com meningioma parasselar ou clival e os acompanharam durante 6 a 32 meses (mediana de 19 meses). Observaram poucas complicações. Ocorreu lenta redução volumétrica do tumor na maioria dos casos. Após 6 meses, em 13 doentes houve pequena redução do volume da lesão, em 4 ocorreu moderada redução volumétrica e, em cinco, os tumores mantiveram-se inalterados. Após 19 meses, ocorreu agravamento das alterações funcionais prévias dos nervos cranianos (diplopia, ptose, paresia facial) em 8 doentes e déficit de nervos cranianos em decorrência da irradiação em 9 . O nervo trigêmeo pareceu ser particularmente sensível, uma vez que 8 doentes apresentaram parestesias faciais manifestandose entre 1 e 24 meses após o tratamento. A dose mediana no nervo óptico foi de $50 \mathrm{~Gy}$ ( $20 \mathrm{~Gy}$ a $100 \mathrm{~Gy}$ ). Não foi observado comprometimento funcional desta estrutura. Na hipófise, a dose mediana foi de 70 Gy (variou de 30 Gy a 150 Gy). Um doente desenvolveu impotência sexual temporária. Na ponte, a dose mediana foi de 70 Gy (variou de 20 Gy a 400 Gy). Um doente, devido ao posicionamento incorreto do isótopo, foi tratado com 400 Gy e desenvolveu déficit de vários nervos cranianos e, tardiamente, hemiparesia ${ }^{222}$. A eficácia da radioterapia intersticial é modesta em tumores extraaxiais da base do crânio recidivados ${ }^{22,86,129}$. Na presente casuística, uma doente com meningioma do tubérculo selar, e com condições cardiocirculatórias insatisfatórias para ser submetida à craniotomia, foi submetida à radioterapia intersticial da lesão e apresentou melhora da função visual 6 meses após o procedimento. $\mathrm{O}$ tratamento de meningiomas com radioterapia intersticial com ${ }^{125} \mathrm{I}$ é, portanto, indicado quando esses tumores não puderem ser ressecados ou quando houver lesão residual que necessite de tratamento adjuvante.

\section{Complicações}

As complicações relacionadas à radioterapia intersticial são representadas por déficits neurológicos, crises convulsivas, dor facial, tromboses arteriais, embolia pulmonar e infecções ${ }^{24}$. Ocorreram complicações em 14,6\% de 41 doentes tratados de gliomas malignos na casuística de Gutin e cols. ${ }^{88}$. Em 1, houve 
piora do déficit neurológico e agravamento da consciência. Na casuística de Willis e cols. ${ }^{234}$ ocorreram complicações em 23,5\% de 17 doentes com gliomas anaplásicos; 1 doente apresentou acentuação da hemiparesia pré-operatória. Salcman e cols. ${ }^{189}$ observaram complicações em $18,8 \%$ de 16 doentes tratados com ${ }^{192} \mathrm{Ir}$; em 2 casos ocorreu acentuação temporária da sonolência e, em 1, acentuação de hemiparesia preexistente.

$\mathrm{Na}$ casuística de Bernstein e cols. ${ }^{24}, 21,7 \%$ dos doentes apresentaram complicações; em 2 ocorreram crises convulsivas, em 1, piora temporária de déficit neurológico preexistente e, em 4, acentuação do déficit neurológico e aumento da pressão intracraniana.

Excluindo-se a instalação ou o agravamento das anormalidades neurológicas pós-operatórias temporárias, que cederam em até 36 horas, as complicações ocorreram com menor freqüência na presente casuística. Foram representadas por 2 casos de osteomielite, 3 de celulite de couro cabeludo e 2 de fístula liquórica. $\mathrm{O}$ número de complicações infecciosas foi maior que a dos autores citados, talvez porque grande número dos doentes foi tratado com técnica de carregamento ulterior, que expõe as estruturas subtegumentares ao meio ambiente durante período de tempo prolongado, facilitando a contaminação. Edema cerebral pode surgir nas primeiras semanas ou muitos meses após a radioterapia intersticial; costuma melhorar com o uso de corticosteróides ${ }^{26}$. Lesões localizadas em regiões de grande importância funcional, tais como córtex motor, núcleo do centro oval e cápsula interna, ou lesões volumosas concorrem para a ocorrência de complicações ${ }^{26}$.

\section{Conclusões}

1. O programa MSPS para uso em computador pessoal é adequado para a realização da radioterapia intersticial em tumores do encéfalo.

2. Não foi observada relação entre localização da lesão, realização ou não da craniotomia e volumes das lesões encefálicas e a curva de probabilidade de sobrevida de doentes tratados com radioterapia intersticial.

3. As variáveis idade superior a 40 anos, índice de Karnofsky igual ou inferior a 70, diagnóstico de glioblastoma multiforme e metástase, realização de telerradioterapia e/ou quimioterapia avaliadas isoladamente correlacionaram-se desfavoravelmente com a probabilidade de sobrevida dos doentes tratados com radioterapia intersticial.
4. A probabilidade de sobrevida de doentes com gliomas de baixo grau e gliomas anaplásicos foi similar.

5. O índice de Karnofsky foi a variável que melhor previu a evolução dos doentes.

6. A probabilidade de sobrevida em 5 anos de doentes com gliomas de baixo grau tratados com radioterapia intersticial foi superior a $50 \%$ e a média de sobrevida foi de 42 meses.

7. A probabilidade de sobrevida em 5 anos dos doentes com astrocitomas anaplásicos tratados com radioterapia intersticial foi superior a $30 \%$ e a média de sobrevida foi de 34 meses.

8. A probabilidade de sobrevida em 2 anos de doentes com glioblastoma multiforme foi superior a $40 \%$ e a média de sobrevida foi de 15 meses.

9. A probabilidade de sobrevida em 1 ano dos doentes com metástases encefálicas tratadas com radioterapia intersticial foi superior a $40 \%$ e a média de vida foi de dez meses.

10. A radioterapia intersticial é procedimento simples e seguro.

\section{Considerações finais}

É difícil avaliar o impacto da radioterapia intersticial na evolução dos doentes com gliomas, metástases e meningiomas sem o concurso de grupos-controle. É necessária, também, a análise de grande número de casos. Segundo Freedman ${ }^{77}$, para avaliar a sobrevida com nível de significância de 0,05 a 0,80 , seriam necessários 1.611 doentes com gliomas anaplásicos distribuídos aleatoriamente. É possível haver diferença no comportamento biológico dos tumores, o que justifica a variabilidade de resultados terapêuticos. No momento, mais do que a natureza histológica dos tumores, a duração da radioterapia intersticial, o momento de executá-la, as conveniências da associação de outros procedimentos adjuvantes, a identificação precisa dos contornos das lesões, a determinação das doses totais e das taxas de doses ideais, da natureza do isótopo apropriado e do volume de lesão mais adequada são questões que necessitam ser esclarecidas.

\section{Referências}

1. ALAMINOS AB, ORTEGA I, MOLINA H, VALLADARES $P$ : A stereotactic surgical planning system for the IBM 386/486 PC family. Stereotact Funct Neurosurg 63:357, 1994. 
2. AL-MEFTY O, FOX JL, SMITH RR: Petrosal approach for petroclival meningiomas. Neurosurgery 22:5107, 1988.

3. AMMIRATI M, VICK N, LIAO Y: Effect of the extend of surgical resection on survival and quality of life in patients with supratentorial glioblastomas and anaplastic astrocytomas. Neurosurgery 21:201-6, 1987.

4. ANDERSEN AP: Postoperative irradiation of glioblastomas. Results in a randomized series. Acta Radiol Oncol 17:475-84, 1978.

5. ANDERSON LL: Dosimetry for interstitial radiation therapy. In Hilaris BS (ed): Handbook of interstitial brachytherapy. Acton, Publishing Services Group, 1975, pp 87-115.

6. ANDERSON LL, NATH R: Interstitial Collaborative Working Group (ICWG), interstitial brachytherapy: physical, biological and clinical considerations. New York, Raven, 1990.

7. ANDREOU J, GEORGE AE, WISE A: CT prognostic criteria of survival after malignant glioma surgery. AJNR 4:488-90, 1983.

8. APUZZO MLJ, CHANDRASOMA PT, COHEN D: Computed imaging stereotaxy: experience and perspective related to 500 procedures applied to brain masses. Neurosurgery 20:930-7, 1987.

9. ARAÚJO LP, SILVA MN, MENEZES AC: Estereotaxia no tratamento dos tumores cerebrais. Experiência inicial em 40 casos. Arq Bras Neurocirurg 16(2):8692, 1997

10. ARBIT E, WRONSKI M: The treatment of brain metastases. Neurosurg Quartely 5(1):1-17, 1995.

11. ARBIT E, WRONSKI M, GALICICH JH: Surgical resection of brain metastases in 670 patients: the Memorial Sloan-Kettering Cancer Center experience, 1972-1992 (Abstract). J Neurosurg 80:386A, 1994.

12. ARONSON SM, GARCIA JH, ARONSON BE: Metastatic neoplasm of the brain metastases. Their frequency in relation to age. Cancer 17:558-62, 1964.

13. AWAD IA, KALFAS I, HAHN JF, LITTLE JR: Intracranial meningiomas in the aged: surgical outcome in the era of computed tomography. Neurosurgery 24:557-60, 1989.

14. AZNAVOORIAN S, MURPHY AN, STETLERSTEVENSON WG, LIOTTA LA: Molecular aspects of tumor cell invasion and metastasis. Cancer 71:136883, 1993.

15. BAILEY P, BUCY PC: Oligodendrogliomas of the brain. Journal of Pathology and Bacteriology 32:73551, 1929

16. BARKER DJP, WELLER RO, GARFIELD JS: Epidemiology of primary tumors of the brain and spinal cord: a regional survey in southern England. $J$ Neurol, Neuros and Psy 39:290-6, 1976.

17. BATEMAN JL, BOND VP, ROBERTSON JS: Doserate dependence of early radiation effects in small mammals. Radiology 79:1008-14, 1962.

18. BEDFORD JS, HALL EJ: Survival of HeLa cells cultured in vitro and exposed to protracted gammairradiation. Int J Radiat Biol 7:377-83, 1963.

19. BEDFORD JS, MITCHELL JB: Mitotic accumulation of HeLa cells during continuous irradiation: observations using time-lapse cinemicrography. Radiat Res 70:173-86, 1977.

20. BERGER MS: Ilustrative case. Techniques in Neurosurgery 2(2):92-6, 1996.

21. BERNSTEIN M, CABANTOG A, LAPERRIERE N, LEUNG P, THOMASON C: Brachytherapy for recurrent single brain metastasis. Can J Neurol Sci 22:13-6, 1995.
22. BERNSTEIN M, GUTIN PH: Interstitial irradiation of brain tumors: a review. Neurosurgery 9(6):741-50, 1981.

23. BERNSTEIN M, LAPERRIERE N, GLEN J, LEUNG $P$, THOMANSON C, LANDON A: Brachytherapy for recurrent malignant astrocytoma. Int $\mathrm{J}$ Radiat Oncol Biol Phys 30:1213-7, 1994.

24. BERNSTEIN M, LAPERRIERE $N$, LEUNG $P$, MCKENZIE S: Interstitial brachytherapy for malignant brain tumors: preliminary results. Neurosurgery 26(3):371-80, 1990b.

25. BERNSTEIN M, LAPERRIERE N, LEUNG P, MCKENZIE S: Interstitial brachytherapy for recurrent solitary cerebral metastases. Can J Neurol Sci 16:237, 1989 (abstr).

26. BERNSTEIN M, MAROTTA T, STEWART P, GLEN J, RESCH L, HENKELMAN M: Brain damage from ${ }^{125}$ brachytherapy evaluated by MR imaging, a bloodbrain barrier tracer, and light and electron microscopy in a rat model. J Neurosurg 73:585-93, 1990a.

27. BERRY RJ, COHEN AB: Some observations on the reproductive capacity of mammalian tumour cells exposed in vivo to gamma radiation at low doserates. Br J Radiol 35:489-91, 1962.

28. BINDAL RK, SAWAYA R, LEAVENS ME, LEE JJ: Surgical treatment of multiple brain metastases. J Neurosurg 79:210-6, 1993.

29. BLACK PM: Solitary brain metastases. Radiation, resection, or radiosurgery? Chest 103(Suppl. 4):3679, 1993.

30. BLEEHEN NM, STENNING SP: A medical research council trial of two radiotherapy doses in the treatment of grades 3 and 4 astrocytoma. $\mathrm{Br} \mathrm{J}$ Cancer 64:769-74, 1991.

31. BLOOM HJG: Intracranial tumors: response and resistence to therapeutic endeavors, 1970-1980. Int J Radiat Oncol Biol Phys 8:1083-113, 1982.

32. BLOOM HJG, GLEES J, BELL J: The treatment and long-term prognosis of children with intracranial tumors: a study of 610 cases, 1950-1981. Int J Radiat Oncol Biol Phys 18:723-45,1990.

33. BLORR RJ, TEMPLETON AW, QUICK RS: Radiation therapy in the treatment of intracranial tumors. AJR 87:463-72, 1962

34. BONITO D, GIARELLI L, FALCONIERI G, BONIFACIOGORI D, TOMASIC G, VIELH P-Association of breast cancer and meningioma. Report of 12 new cases and review of the literature. Pathol Res Pract 189:399-404, 1993.

35. BOOGERD W, DALESIO O, BAIS EM, VAN DER SANDE J: Response of brain metastases from breast cancer to systemic chemotherapy. Cancer 69:972-80, 1992.

36. BOOGERD W, VOS VW, HART AAM, BARIS G: Brain metastases in breast cancer; natural history, prognostic factors and outcome. J Neurooncol 15:165-74, 1993.

37. BORGELT B, GELBER R, KRAMER S: The palliation of brain metastases: final results of the first two studies by the radiation therapy oncology group. Int $\mathrm{J}$ Radiat Oncol Biol Phys 6:1-9, 1980.

38. BOUCHARD J: Radiation therapy of intracranial tumors: long term results. Acta Radiol 5:11-6, 1966.

39. BRAUCH CL: Multiple brain metastases: are they surgical lesions? Perspect Neurol Surg 1:35-44, 1990.

40. BRENEMAN J, SAWAYA R: Cerebral radiation necrosis. Perspect Neurol Surg 2:127-42, 1991.

41. BROWN JM: Evidence for acutely hypoxic cells in mouse tumors, and a possible mechanism of reoxygenation. Br J Radiol 52:650-6, 1979. 
42. BUCKNER JC: The role of chemotherapy in the treatment of patients with brain metastases from solid tumors. Cancer Metastasis Rev 10:335-41, 1991.

43. BURT M, WRONSKI M, ARBIT E, GALICICH JH: Resection of brain metastases from non-small-cell lung carcinoma. J Thorac Cardiovasc Surg 103:399411, 1992.

44. BUTLER AB, NETSKY MG: Classification and biology of brain tumors. In Youmans JR (ed): Neurological surgery. Philadelphia, N.B. Saunders Company, 1973, pp 1297-339.

45. CAIRNCROSS JG, KIM JH, POSNER JB: Radiation therapy for brain metastases. Ann Neurol 7:529-41, 1980.

46. CAIRNCROSS JG, POSNER JB: The management of brain metastases. In Walker MD (ed): Oncology of the nervous system. Hingham, Martinius Nijhoff, 1983, pp 341-78.

47. CHANG $\mathrm{CH}$, HORTON J, SCHOENFELD D: Comparison of postoperative radiotherapy and combined postoperative radiotherapy and chemotherapy in the multidisciplinary management of malignant gliomas. A joint radiation therapy oncology group and eastern cooperative oncology group study. Cancer 52:997-1007, 1983

48. CHIN HW, FRUIN AH, ESTES TR, JAEGER S, TAYLON $C$ : Technical application of stereotactic irradiation in malignant brain tumors. Stereotact Funct Neurosurg 56:135-43, 1991.

49. CHIN HW, MARUYAMA Y, YOUNG AB: A clinical study with brain brachytherapy for malignant gliomas. Stranhlenther Onkol 162:433-6, 1986.

50. CHIN HW, MARUYAMA Y, YOUNG AB: Intracerebral neutron brachytherapy for hemispheric glioblastoma multiforme: a pilot study. J Neurooncol 2:341-7, 1984.

51. CHIN HW, MARUYAMA Y, YOUNG AB: Intracerebral neutron brachytherapy: the technique and application for malignant brain tumors. Endocuriether Hyperther Oncol 1:229-36, 1985.

52. CIRIC I, AMMIRATI M, VICK N: Supratentorial gliomas: surgical considerations and immediate postoperative results. Gross total resection versus partial resection. Neurosurgery 21:21-6, 1987.

53. CLOUSTON PD, DeANGELIS LM, POSNER JB: The spectrum of neurological disease in patients with systemic cancer. Ann Neurol 31:268-73, 1992.

54. COCCONI G, LOTTICI R, BISAGNI G, BACCHI M, TONATO M, PASSALACQUA R et al:: Combination therapy with platinum and etoposide of brain metastases from breast carcinoma. Cancer Invest 8:327-34, 1990

55. COFFEY RJ, LUNSFORD LD, TAYLOR FH: Survival after stereotactic biopsy of malignant gliomas. Neurosurgery 22:465-73, 1988.

56. COHEN A, MODAN B: Some epidemiologic aspects of neoplastic diseases in Israeli immigrant population. III. Brain tumors. Cancer 22:1323-8, 1968.

57. COIA LR: The role of radiation therapy in the treatment of brain metastases. Int $\mathrm{J}$ Radiat Oncol Biol Phys 23:229-38, 1992

58. COULDWELL WT, HINTON DR: Oligodendroglioma. In Kayne AH, Laws Jr. ER (eds): Brain tumors. Edinburgh, Churchill Livingstone, 1995, pp 479-91.

59. COX DR: Regression models and life tables. J R Stat Soc 2:187-220, 1972.

60. DAVIS L, MARTIN J, GOLDSTEIN SL: A study of 211 patients with verified glioblastoma multiforme. J Neurosurg 6:33-44, 1949.
61. DeANGELIS LM, DELATTRE JY, POSNER JB: Radiation-induced dementia in patients cured of brain metastasis. Neurology 39:789-96, 1989.

62. DELATTRE JY, KROL G, THALER HT, POSNER JB: Distribution of brain metastases. Arch Neurol 45:7414, 1988.

63. DeMONTE F, SMITH HK, AL-MEFTY O: Outcome of aggressive removal of cavernous sinus meningiomas. J Neurosurg 81:245-51, 1994.

64. DHOPESH VP, YAGNIK PM: Brain metastasis: analysis of patients without known cancer. South Med J 78:171-2, 1985

65. DOHRMANN GJ, FEARWELL JR, FLANNERY JT: Astrocytomas in childhood: a population-based study. Surg Neurol 23:64-8, 1985.

66. DRINGS P, RIZI B, ABEL G, VAN KAICK G: The frequency of brain metastases in small cell lung cancer [in German]. Prax Klin Pneumol 41:695-6, 1987.

67. EGAWA S, TUKIYAMA I, AKINE Y: Radiotherapy of brain metastases. Int J Radiat Oncol Biol Phys 12:1621-5, 1986.

68. ELKIND MM: Repair processes in radiation biology. Radiat Res 100:425-49, 1984.

69. ENGENHART R, KIMMIG BN, HOVER KH: Long-term follow-up for brain metastases treated by percutaneous stereotactic single high-doseirradiation. Cancer 71:1353-61, 1993.

70. ETOU A, MUNDINGER F, MOHAJDER M, BIRG W: Stereotactic interstitial irradiation of diencephalic tumors with iridium-192 and iodine-125: 10 years follow-up and comparison with other treatments. Child Nerv Syst 5:140-3, 1989.

71. EYRE HJ, CROWLEY JJ, TOWNSEND JJ, ELTRINGHAM JR, MORANTZ RA, SCHULMAN SF et al.: A randomized trial of radiotherapy plus CCNU for incompletely resected low-grade gliomas: a Southwest Oncology Group Study. J Neurosurg 78:909-14, 1993.

72. FLETCHER GH: Clinical dose-response curves of human malignant epithelial tumours. $\mathrm{Br} \mathrm{J}$ Radiol 46:1-12, 1973.

73. FLETCHER GH, FLETCHER SW, WAGNER EH: Clinical epidemiology - the essentials. Ed 2. Baltimore, Williams \& Wilkins, 1988, pp 172-87.

74. FLICKINGER JC, LOEFFLER JS, LARSON DA: Sterotactic radiosurgery for intracranial malignancies. Oncology 82:81-6, 1994.

75. FLOWERS A, LEVIN VA: Management of brain metastases from breast carcinoma. Oncology 7:21-6, 1993.

76. FRANKEL SA, GERMAN WJ: Glioblastoma multiforme: review of 219 cases with regard to natural history, pathology, diagnostic methods, and treatment. J Neurosurg 15:489-503, 1958.

77. FREEDMAN LS: Tables of the number of patients required in clinical trials using the logrank test. Stat Med 1:121-9, 1982

78. GADEMANN G, ENGENHART R, SCHLEGEL W, KIMMIG BN, HÖVER KH, LORENZ W et al.: Results and comparison of single dose and fractionated stereotactic radiotherapy in 87 low grade meningiomas. In: Proceedings of The Annual Meeting of The American Society for Therapeutic Radiology and Oncology, $35^{\text {th }}$. Int J Radiat Oncol Biol Phys 27:153-4, 1994.

79. GALICICH JH, ARBIT E, WRONSKI M: Metastatic brain tumors. In Wilkins RH \& Rengachary SS (eds): Neurosurgery. Ed 2. New York, McGraw-Hill, 1995. 
80. GALICICH JH, SUNDARESAN N, ARBIT E, PASSE S: Surgical treatment of single brain metastasis: factors associated with survival. Cancer 45:381-6, 1980.

81. GARCIA DM, FULLING KH, MARKS JE: The value of radiation therapy in addition to surgery for astrocytomas of the adult cerebrum. Cancer 55:91927, 1985.

82. GLANZMANN CH: Palliative radiotherapie von Hirnmetastasen solider tumoren: erfahrungen mit hohen dosen. Strahlenther Onkol 66:119-24, 1990.

83. GRANT D, EDWARDS D, GOLDSTRAW P: Computed tomography of brain, chest, and abdomen in the preoperative assessment of non-small cell lung cancer. Thorax 43:883-6, 1988.

84. GUTHRIE LB, LAWS Jr. ER: Supratentorial low-grade gliomas. Neurosurgery Clinics of North America 1(1):37-48, 1990.

85. GUTIN PH, BARBARO NM, LEIBEL SA: Special stereotactic techniques - stereotatic interstitial brachytherapy. In Heilbrun MP (ed): Concepts in neurosurgery: stereotactic neurosurgery. Baltimore, William \& Wilkins, 1988, pp 241-6.

86. GUTIN PH, LEIBEL SA: Stereotaxic interstitial irradiation of malignant brain tumors. Neurol Clin 3:883-93, 1985

87. GUTIN PH, LEIBEL SA, HOSOBUCHI Y, CRUMLEY RL, EDWARDS MSB, WILSON CB et al.: Brachytherapy of recurrent tumors of the skull base and spine with iodine-125 sources. Neurosurgery 20:938-45, 1987a.

88. GUTIN PH, LEIBEL SA, WARA WM, CHOUCAIR A, LEVIN VA, PHILIPS TL et al.: Recurrent malignant gliomas: survival following interstitial brachytherapy with high-activity iodine-125 sources. J Neurosurg 67:864-73, 1987b.

89. GUTIN PH, PHILLIPS TL, HOSOBUCHI Y, WARA WM, MACKAY AR, WEAVER KA et al.: Permanent and removable implants for the brachytherapy of brain tumors. Int J Radiat Oncol Biol Phys 7:1371-81, 1981.

90. GUTIN PH, PHILIPS TL, WARA WM, LEIBEL SA, HOSOBUCHI Y, LEVIN VA et al.: Brachytherapy of recurrent malignant brain tumors with removable high-activity iodine-125 sources. J Neurosurg 60:618, 1984.

91. GUTIN PH, WARA WM, PHILLIPS TL: Hypoxic cell radiosensitizers in the treatment of malignant brain tumors. Neurosurgery 6:567-76, 1980.

92. HAGLUND MM, BERGER M: Functional mapping of motor, sensory and language pathways during lowgrade glioma removal. Techniques in Neurosurgery 2(2):141-9,1966.

93. HAKIM R, ALEXANDER III E, LOEFFLER JS, SHRIEVE DC, WEN P, FALLON MP et al:: Results of linear accelerator-based radiosurgery for intracranial meningiomas. Neurosurgery 42(3):446-54, 1998.

94. HALL EJ: Radiation dose-rate: a factor of importance in radiobiology and radiotherapy. $\mathrm{Br} \mathrm{J}$ Radiol 45:8197, 1972

95. HALL EJ: Radiobiology for the radiologist. Ed 2. Hagerstown, Harper and Row Publishers, 1978a.

96. HALL EJ: The promise of low dose rate: has it been realized? Int J Radiat Oncol Biol Phys 4:749-50, 1978b.

97. HALL EJ, BEDFORD JS: Dose rate: its effect on the survival of HeLa cells irradiated with gamma-rays. Radiat Res 22:305-15, 1964

98. HALL EJ, BEDFORD JS, OLIVER R: Extreme hypoxia: its effect on the survival of mammalian cells irradiated at high and low dose-rates. $\mathrm{Br} \mathrm{J}$ Radiol 39:302-7, 1966a.
99. HALL EJ, CAVANAGH J: The oxygen effect for acute and protracted radiation exposures measured with seedlings of Vicia faba. Br J Radiol 40:128-33, 1967.

100. HALL EJ, ROSSI HH, ROIZIN LA: Low-dose-rate irradiation of mammalian cells with radium and californium-252: a comparison of effects on an actively proliferating cell population. Radiology 99:445-51, 1971.

101. HAMANN G, MEIER T, SCHMIRIGK K: Brain metastases as primary manifestation of malignancy [in German]. Nervenarzt 64:104-7, 1993.

102. HENSON RA, URICH H: Cancer and the nervous system: the neurological manifestations of systemic malignant disease. Oxford, Blackwell Scientific, 1982, pp 3-58.

103. HEROS DO, KASDON DL, CHUN M: Brachytherapy in the treatment of recurrent solitary brain metastases. Neurosurgery 23:733-7, 1988.

104. HIGASHI H, MATSUMOTO K, NAKAGAWA M, TSUNO K, FURUTA J, OHMOTO T: Two cases of metastatic brain tumor treated by interstitial brachytherapy. No Shinkei Geka 21:729-33, 1993.

105. HILL RP, BUSH RS: The effect of continuous or fractionated irradiation on a murine sarcoma. $\mathrm{Br} J$ Radiol 46:167-74, 1973.

106. HIRAKAWA K, SUZUKI K, UEDA S: Multivariate analysis of factors affecting postoperative survival in malignant astrocytoma. J Neuro Oncol 2:331-40, 1984

107. HITCHCOCK E, SATO F: Treatment of malignant glioma. J Neurosurg 21:497-505, 1964.

108. HOFFMAN HJ: Optic and hypothalamic gliomas. Techniques in Neurosurgery 2(3):194-203,1996.

109. HOLT G, HILARIS B, BALTER S, RAGAZZONI GD, PHILLIPS RF, LAUGHLIN JS: Experience with computerized implant dosimetry. AJR 102:688-93, 1968.

110. JÄÄSKELÄINEN J: Seemingly complete removal of histologically benign intracranial meningioma: late recurrence rate and factors predicting recurrence in 657 patients. A multivariate analysis. Surg Neurol 26:461-9, 1986

111. JACOBS L, KINKEL WR, VINCENT RG: "Silent" brain metastasis from lung carcinoma determined by computerized tomography. Arch Neurol 34:690-3, 1977.

112. JAECKLE KA: Causes and management of headaches in cancer patients. Oncology 7:27-31, 1993

113. JELSMA R, BUCY PC: Glioblastoma multiforme. Its treatment and some factors effecting survival. Arch Neurol 20:161-71, 1969.

114. JELSMA R, BUCY PC: The treatment of glioblastoma multiforme of the brain. J Neurosurg 27:388-400, 1967.

115. JUBELIRER SJ, RUBIN M, SHIM C: An analysis of 38 cases of low-grade cerebral astrocytoma in adults. West Va Med J 89:102-5, 1993.

116. KAL HB, BARENDSEN GW: Effects of continuous irradiation at low dose-rates on a rat rhabdomyosarcoma. Br J Radiol 45:279-83, 1972.

117. KAPLAN EL, MEIER P: Nonparametric estimation from incomplete observations. J Am Stat Assoc 53:457-81, 1958

118. KAYE AH, LAWS Jr. ER: Historical perspective. In Kaye AH, Laws Jr. ER: Brain tumors. Edinburgh, Churchill Livingstone, 1995, pp 3-8.

119. KELLY PJ: Computed tomography and histologic limits in glial neoplasmas: tumor types and selection form volumetric resection. Surg Neurol 39:458-65, 1993. 
120. KIM JH, HILARIS B: lodine 125 source in interstitial tumor therapy: clinical and biologic considerations. AJR 123:163-9, 1975.

121. KINSELLA TJ, ROWLAND CJ, KLECKER R: Pharmacology and phase I/II study of continuous intravenous infusions of iododeoxyuridine and hyperfractionated radiotherapy in patients with glioblastoma multiforme. J Clin Oncol 6:867-79, 1988.

122. KIRICUTA IC, KÖLBL O, WILLNER J, BOHNDORF W: Central nervous system metastases in breast cancer. J Cancer Res Clin Oncol 118:542-6, 1992.

123. KONDZIOLKA D, LUNSFORD LD, COFFEY RJ, FLICKINGER JC: Stereotactic radiosurgery of meningiomas. J Neurosurg 74:552-9, 1991.

124. KORMAS P, BRADSHAW JR, JEYASINGHAM K: Preoperative computed tomography of the brain in non-small cell bronchogenic carcinoma. Thorax 47:106-8, 1992

125. KRAMER ED, LEWIS D, RANEY B, WOMER R, PACKER RJ: Neurologic complications in children with soft tissue and osseous sarcoma. Cancer 64:26003, 1989.

126. KRAMER S: Radiation therapy in the management of malignant gliomas. Proc Natl Cancer Conf 7:8236, 1973.

127. KRETH FW, FAIST M, WARNKE PC, ROSSNER R, VOLK B, OSTERTAG CB: Interstitial radiosurgery of low-grade gliomas. J Neurosurg 82:418-29, 1995.

128. KRISHNASWAMY V: Dose distribution around an ${ }^{125}$ seed source in tissue. Radiology 126:489-91, 1978.

129. KUMAR PP, GOOD RR, LEIBROCK LG, MAWK JR, YONKERS AJ, OGREN FP: High activity iodine 125 endocurietherapy for recurrent skull base tumors. Cancer 61:1518-27, 1988

130. KUMAR PP, PATIL AA, SYH H-W, CHU W-K, REEVES $M A$ : Role of brachytherapy in the management of skull base meningiomas. Treatment of skull base meningiomas. Cancer 71:3726-31, 1993.

131. KURTZ JM, GELBER R, BRADY LW, CARELLA RJ, COOPER JS: The palliation of brain in a favorable patient population: a randomized clinical trial by the Radiation Therapy Oncology Group. Int J Radiat Oncol Biol Phys 7:891-5, 1981.

132. LAJTHA LG, OLIVER R: Some radiobiological considerations in radiotherapy. Br J Radiol 34:252-7, 1961.

133. LAMERTON LF: Cell proliferation under continuous irradiation. Radiat Res 27:119-38, 1966.

134. LAWS Jr. ER, TAYLOR WF, CLIFTON MB: The neurosurgical management of low-grade astrocytoma. Clin Neurosurg 33:375-590, 1985

135. LAWS Jr. ER, TAYLOR WF, CLIFTON MB, OKAZAKI $\mathrm{H}$ : Neurosurgical management of low-grade astrocytoma of the cerebral hemipheres. J Neurosurg 61:665-73, 1984

136. LEIBEL SA, GUTIN PH, WARA WM: Survival and quality of live after intersticial implantation of removable high-activity iodine-125 sources for the treatment of patients with recurrent malignant gliomas. Int J Radiat Oncol Bio Phy 17:1129-39, 1989.

137. LEKSELL L: A stereotaxic apparatus for intracerebral surgery. Acta Chir Scand 99:229-33, 1949.

138. LING CC, ANDERSON LL, SHIPLEY WU: Dose inhomogeneity in interstitial implants using ${ }^{125}$ / seeds. Int J Radiat Oncol Biol Phys 5:419-25, 1979.

139. LING CC, CHUI CS: Stereotactic treatment of brain tumors with radioactive or external photon beams: radiobiophysical aspects. Radiother Oncol 26:11-8, 1993

140. LOEFFLER JS, ALEXANDER III E: Radiosurgery for the treatment of intracranial metastases. In Alexander III E, Loeffler JS, Lunsford LD (eds): Stereotactic radiosurgery. New York, McGraw-Hill, 1993, pp $197-$ 206.

141. MAHALEY MS, METTLIN C, NATARAJAN: Nationa survey of patterns of care for brain tumor patients. $J$ Neurosurg 71:826-36, 1989.

142. MAOR MH, FRIAS AE, OSWALD MJ: Palliative radiotherapy for brain metastases in renal carcinoma. Cancer 62:1912-7, 1988

143. MAURICE-WILLIAMS RS, KITCHEN ND: Intracranial tumours in the elderly: the effect of age on the outcome of first time surgery for meningiomas. $\mathrm{Br} J$ Neurosurg 6:131-7, 1992

144. McCORMACK BM, MILLER DC, BUDZILOVICH GN, VOORHEES GJ, RANSOHOFF J: Treatment and survival of low-grade astrocytoma in adults: 19771988. Neurosurgery 31:636-42, 1992.

145. MEDBURY CA, STRAUS KL, STEINBERG SM: Lowgrade astrocytomas: treatment results and prognostic variables. Int J Radiat Oncol Biol Phys 15:837-41, 1988.

146. MERCHUT MP: Brain metastases from undiagnosed systemic neoplasms. Arch Intern Med 149:1076-80, 1989.

147. MOSER RP, JOHNSON ML, YUNG IV A: Metastatic brain cancer in patients with no known primary site. Cancer Bull 41:173-7, 1989

148. NADALIN W, TEIXEIRA MJ, WELTMAN E, AGUILAR PB: Radioterapia dos tumores do sistema nervoso central. In Siqueira MG, Novaes V: Tumores intracranianos: biologia, diagnóstico e tratamento. São Paulo, Revinter, 1999, pp 441-52.

149. NATH R, MELILLO A: Dosimetric characteristics of double wall ${ }^{125}$ source for interstitial brachytherapy. Med Phys 20, 1993.

150. NELSON DF, NELSON JS, DAVID DR: Survival and prognosis of patients with astrocytoma with atypical or anaplastic features. J Neurooncol 3:99-103, 1985.

151. NETSKY MG, AUGUST B, FOWLER W: The longevity of patients with glioblastoma multiforme. J Neurosurg 7:261-9, 1950.

152. NEWELL J, RANSOHOFF J, KAPLAN B: Glioblastoma in the older patient. How long a course of radiotherapy is necessary? J Neurooncol 6:325-7, 1988

153. NIAS AHW, HOWARD A, GREENE D, MAJOR D: The response of chinese hamster (ovary) cells to protracted irradiation from ${ }^{252} \mathrm{Cf}$ and ${ }^{60} \mathrm{Co}$. Br J Radiol 46:991-5, 1973.

154. NORTHFIELD DWC: The surgery of the central nervous system: a textbook for postgraduate students. London, Blackweel, 1973, 884p.

155. OHAEGBULA SC, SADDEQI N, IKERIONWU S: Intracranial tumors in Enugu, Nigeria. Cancer 46:2322-4, 1980

156. OSTERTAG CB: Radiation implants for low-grade gliomas. Techniques in Neurosurgery 2(3):174-82, 1996.

157. OSTERTAG CB, KRETH FW: lodine-125 interstitial irradiation for cerebral gliomas. Acta Neurochir (Wien) 119:53-61, 1992

158. OSTERTAG CB, MENNEL HD, KIESSLING M: Stereotactic biopsy of brain tumors. Surg Neurol 14:275-83, 1980 .

159. OSTERTAG CHB: Stereotactic interstitial radiotherapy for brain tumors. J Neurosurg Sci 33:83-9, 1989. 
160. PATCHELL RA, TIBBS PA, WALSH JW: A randomized trial of surgery in the treatment of single metastases to the brain. N Engl J Med 322:494-500, 1990.

161. PAYNE DG, SIMPSON WJ, KEEN C, PLATTS ME: Malignant astrocytoma. Hyperfractionated and standard radiotherapy with chemotherapy in a randomized prospective clinical trial. Cancer 50:2301-6, 1982.

162. PEIRCE CB: The efficacy of radiation therapy in the treatment of tumors of the brain and brain stem. Clin Neurosurg 10:195-211, 1964.

163. PENAR PL, WILSON JT: Cost and survival analysis of Metastatic cerebral tumors treated by resection and radiation. Neurosurgery 34:888-94,1994.

164. PHILIPPON JH, CLEMENCEAU S, FAUCHON FH, FONCIN JF: Supratentorial low-grade astrocytomas in adults. Neurosurgery 32:554-9, 1993.

165. PHILLIPS M: Stereotactic radiosurgery: introduction to the physical aspects. In Phillips M (ed): Physical aspects of stereotactic radiosurgery. New York, Plenum Press, 1993, pp 1-44.

166. POOL JL, KAMRIN RP: The treatment of intracranial gliomas by surgery and radiation. Prog Neurol Surg 1:258-99, 1966.

167. POSNER JB: Brain metastasis: a clinician's view. In Weiss L, Gilbert HA, Posner JB (eds): Brain metastasis. Boston, GK Hall, 1980, pp 2-29.

168. POSNER JB: Management of brain metastases. Rev Neurol 148:477-87, 1992a.

169. POSNER JB, CHERNIK NL: Intracranial metastases from systemic cancer. Adv Neurol 19:579-92, 1978.

170. POSTMUS PE, SLEIJFER DT, HAAXMA-REICHE H: Chemotherapy for central nervous system metastases from small cell lung cancer: a review. In Hansen $\mathrm{HH}$, Kristjansen PEG (eds): Management of small cell lung cancer. Amsterdam, Elsevier, 1989, pp 136-45.

171. POSTMUS PE, SMIT EF, HAAXMA-REICHE H: Treatment of central nervous system metastases from small cell lung cancer with chemotherapy. Lung Cancer 9:281-6, 1993.

172. PRADOS M, LEIBEL SA, BARNETT CM, GUTIN PH: Interstitial brachytherapy for metastatic brain tumors. Cancer 63:657-60, 1989.

173. PUCK TT, MARCUS PI: Action of $x$-rays on mammalian cells. J Exp Med 103:653-66, 1956.

174. QUIÑONES-MOLINA R, ALAMINOS A, MOLINA H, MUÑOZ J, LOPEZ G, ALVAREZ L et al.: Computerassisted CT-guided stereotactic biopsy and brachytherapy of brain tumors. Stereotact Funct Neurosurg 63:52-5, 1994.

175. ROBERT WR, PURI RK, HOON DS, LELAND P, SNOY $P$, PASTAN I et al.: Preclinical development of a recombinant toxin containing circularly permuted interleukin 4 and truncated pseudomonas exotoxin for therapy of malignant astrocytoma. Cancer Reserch 56:5631-7, 1997.

176. ROSEN II, LANE RG, KELSEY CA: Computation of dose distributions for radioactive seed implants. Acta Radiol Oncol 19(1):41-4, 1980.

177. ROSNER D, NEMOTO T, LANE WW: Chemotherapy induces regression of brain metastases in breast carcinoma. Cancer 58:832-9, 1986.

178. ROTH JG, ELVIDGE AR: Glioblastoma multiforme: a clinical survey. J Neurosurg 17:736-50, 1960.

179. RUBINSTEIN LJ: Oligodendrogliomas. In Tumor on the central nervous system. Washington DC, Armed Forces Institute of Pathology, 1972, pp 85-104.

180. RUSTIN GJS, NEWLANDS ES, BAGSHAWE KD: Successful management of metastatic and primary germ cell tumors in the brain. Cancer 57:2108-13, 1986.
181. RUTTEN EHJM, KAZEN I, SLOOFF JL: Postoperative radiation therapy in the management of brain astrocytomas: retrospective study of 142 patients. Int J Radiat Oncol Biol Phys 7:191-5, 1981.

182. SALAZAR OM, RUBIN P, FELDSTEIN ML: High-dose radiation therapy in the treatment of malignant gliomas: final report. Int J Radiat Oncol Biol Phys 5:1733-40, 1979.

183. SALCMAN M: Astrocitomas cerebrais de baixo grau de malignidade em adultos. In Siqueira MG, Novaes $\checkmark$ (eds): Tumores intracranianos: biologia, diagnóstico e tratamento. São Paulo, Revinter, 1999, pp 168-77.

184. SALCMAN M: Glioblastoma and malignant astrocytoma. In Andrew HK, Edward R, Laws Jr. (eds): Brain tumors. NewYork, Churchill Livingstone, 1995 , pp 449-77.

185. SALCMAN M: Survival in glioblastoma: historical perspective. Neurosurgery 7:435-9, 1980.

186. SALCMAN M: The morbidity and mortality of brain tumors: a perspective on recent advances in therapy. Neuro Clin 3:1-29, 1985c

187. SALCMAN M: The neurobiology of brain tumors: concepts in neurosurgery. Baltimore, William \& Wilkins, 1991, pp 386.

188. SALCMAN M: The unconscious patient. In Salcman $M$ (ed): Neurologic emergencies, recognition and management. Ed 2. New York, Raven Press, 1990, pp 17-38.

189. SALCMAN M, SEWCHAND W, AMIN P: CT-guided stereotactic surgery and interstitial irradiation for glial tumors. J Neurooncol 2:279-82, 1984.

190. SALFORD LG, BRUN A, NIRFALK S: Ten-year survival among patients with supratentorial astrocytomas grade III and IV. J Neurosurg 69:506-9, 1988.

191. SALVAJOLI JV: Radiocirurgia com acelerador linear de partículas e resultados em metástases cerebrais. Tese (Doutorado). Universidade Federal de São Paulo - Escola Paulista de Medicina, São Paulo, 1998.

192. SAMII M, AMMIRATI M, MAHRAN A, BINI W, SEPEHRNIA A: Surgery of petroclival meningiomas: report of 24 cases. Neurosurgery 24:12-7, 1989.

193. SANDEMAN DR, SANDEMAN AP, BUSTON P: The management of patients with an intrinsic brain tumor. British J Neurosurgery 4:299-312, 1990.

194. SCAFF LAM: Braquiterapia. In Scaff LAM (ed): Física da radioterapia. São Paulo, Sarvier, 1997, pp 25382.

195. SCANLON PW, TAYLOR WF: Radiotherapy of intracranial astrocytomas: analysis of 417 cases treated from 1960 trough 1969. Neurosurgery 5:3018, 1979.

196. SCOTT GM, GIBBERD FB: Epilepsy and other factors in the prognosis of gliomas. Acta Neurol Scand 61:227-39, 1980

197. SELKER RG: Intracranial metastatic disease: development of a surgical philosophy. In Long DM (ed): Current therapy in neurological surgery: 2 . Toronto, Decker, 1989, pp 54-6.

198. SHAW EG: Low-grade gliomas. To treat or not to treat? A radiation oncologist's viewpoint. Arch Neurology 47:1138-9, 1990.

199. SHAW EG, DAUMAS-DUPORT C, SCHEITHAUER BW, GILBERTSON DT, O'FALLON JR et al.: Radiation therapy in the management of low-grade supratentorial astrocytomas. J Neurosurg 70(6):853-61, 1989.

200. SHELINE GE: Radiation therapy of primary tumors. Semin Oncol 2:29-42, 1975. 
201. SIEGERS HP: Chemotherapy for brain metastases: recent developments and clinical considerations. Cancer Treat Rev 17:63-76, 1990.

202. SMALLEY SR, LAWS ERJr., O'FALLON JR, SHAW EG, SCHRAY MF: Resection for solitary brain metastasis: role of adjuvant radiation and prognostic variables in 229 patients. J Neurosurg 77:531-40, 1992.

203. SMITH DF, MUTTON JL, SANDEMANN D, FOY PM, SHAW MD, WILLIAMS IR et al.: The prognosis of primary intra cerebral tumors presenting with epilepsy: the outcome of medical and surgical management. J Neurol Neurosurg Psy 54:915-20, 1991.

204. SNEED PK, PRADOS MD, MCDERMOTT MW, LARSON DA, MALEC MK, LAMBORN KR et al.: Large effect of age on the survival of patients with glioblastoma treated with radiotherapy and brachytherapy boost. Neurosurgery 36(5):898, 1995.

205. SOFFIETTI R, CHIO A, GIORDANA MT, VASARIO E, SCHIFFER D: Prognostic factors in well-differentiated cerebral astrocytomas in the adult. Neurosurgery 24(5):689-92, 1989.

206. SOMAZA S, KONDZIOLKA D, LUNSFORD LD, KIRKWOOD JM, FLICKINGER JC: Stereotactic radiosurgery for cerebral metastatic melanoma. J Neurosurg 79:661-6, 1993.

207. SPETZLER RF, DASPIT CP, PAPPAS CTE: The combined supra-and infratentorial approach for lesions of the petrous and clival regions: experience with 46 cases. J Neurosurg 76:588-99, 1992.

208. SUBACH BR, LUNSFORD LD, KONDZIOLKA D, MAITS $A H$, FLICKINGER JC: Management of petroclival meningiomas by stereotactic radiosurgery. Neurosurgery 42(3):437-45, 1998

209. SUNDARESAN N, GALICICH JH: Brain metastases from colon cancer. Proc ASCO 5:268, 1986.

210. SZIKLA G, SCHLIENGER M, BLOND S, DUMASDUPORT C, MISSIR O, MIYAHARA $S$ et al.: Interstitial and combined interstitial and external irradiation of supratentorial gliomas: results in 61 cases treated 19731981. Acta Neurochir Suppl (Wien) 33:355-62, 1984.

211. TAKAKURA K, SANO H, HOJO S, HIRANO A: Metastatic tumors of the central nervous system. Tokyo, Igaku-Shoin, 1982, pp 112-8.

212. TALLY PW, LAWS Jr. ER, SCHEITHAUER BW: Metastases of central nervous system neoplasms. Case report. J Neurosurg 68:811-6, 1988.

213. TAVERAS JM, THOMPSON HGJr., POOL JL: Should we treat glioblastoma multiforme? A study of survival in 425 cases. AJR 87:473-9, 1962

214. TEIXEIRA MJ, AGUIAR PH, CORREAA CF, SOUZA EC, CESCATO WA: Remoção estereotomográfica de lesões encefálicas sob anestesia local. Arq Bras Neurocirurg 11(4):191-200, 1992.

215. TEIXEIRA MJ, OLIVEIRA Jr JO, BANKOVYSKY I, LEITÃO H, BARROS NG, NAKAGAWA EJ et al.: Esterotomografia para o diagnóstico e localização das lesões encefálicas profundas. Arq Bras Neurocirurg 7:39-45, 1988

216. TEN HAKEN AK, DIAZ RF, McSHAN DL, FRAASS BA, TAREN JA, HOOD TW: From manual to 3-D computerized treatment planning for 125-1 stereotactic brain implants. Int J Radiat Oncol Biol Phys 15:467-80, 1988

217. THOMSON JF, TOURTELLOTTE WW: The effect of dose rate on the $L_{50}$ of mice exposed to gamma radiation from cobalt 60 sources. AJR 69:826-9, 1953.

218. TROUILLAS P, MENAUD G: Etude epidemiologique des tumeurs primitives du neuraxe dans la region Rhone-Alphe. Rev Neurol 131:691-708, 1975
219. UIHLEIN A, COLBY MYJr., LAYTON DD, PARSONS WR, CARTER TL: Comparison of surgery and surgery plus irradiation in the treatment of supratentorial gliomas. Acta Radiol (Ther) 5:67-79, 1966.

220. VALK FE, BUDINGER TF, LEVIN VA, SILVER P, GUTIN $\mathrm{PH}$, DOYLE WK: PET of malignant cerebral tumors after interstitial brachytherapy. Demonstration of metabolic activity and correlation with clinical outcome. J Neurosurg 69:830-8, 1988.

221. van PUTTEN LM, KALLMAN RF: Oxygenation status of a transplantable tumor during fractionated radiation therapy. J Natl Cancer Inst 40:441-51, 1968.

222. VUORINEN V, HEIKKONEN J, BRANDER A, SETÄLÄ $\mathrm{K}$, SANE T, RANDELL $T$ et al.: Interstitial radiotherapy of 25 parasellar / clival meningiomas and 19 meningiomas in the elderly: analysis of short- term tolerance and responses. Acta Neurochir (Wien) 138:495-508, 1996.

223. WALKER MD, ALEXANDER Jr. E, HUNT WE: Evaluation of BCNU and / or radiotherapy in the treatment of anaplastic gliomas: a cooperative clinical trial. J Neurosurg 49:333-43, 1978.

224. WALKER MD, ALEXANDER Jr. E, HUNT WE: Evaluation of mithramycin in the treatment of anaplastic gliomas. J Neurosurg 44:655-67, 1976.

225. WALKER MD, GREEN SB, BYAR DP: Randomized comparisons of radiotherapy and nitrosoureas for the treatment of malignant glioma after surgery. $\mathrm{N}$ Eng $\mathrm{J}$ Med 303:1323-9, 1980.

226. WALKER MD, STRIKE TA, SHELINE GE: An analysis of dose-effect relationship in the radiotherapy of malignant gliomas: for the Brain Tumor Study Group (BTSG). Int J Radiat Oncol Biol Phys 5:1725-31, 1979.

227. WALKER RW, POSNER JB: Central nervous system neoplasms. Curr Neurol 5:285-320, 1984.

228. WARA WM, SHELINE GE: Radiation therapy of malignant brain tumor. Clin Neurosurg 25:397-402, 1978.

229. WEAVER KA: The dosimetry of $\mathrm{I}-125$ seed eye plaques. Med Phys 13:78-83, 1986.

230. WEIR B: The relative significance of factors affecting postoperative survival in astrocytomas, grades 3 and 4. J Neurosurg 38:448-52, 1973.

231. WEST J, MAOR M: Intracranial metastases: behavioral patterns related to primary site and results of treatment by wholw brain irradiation. Int $\mathrm{J}$ Radiat Oncol Biol Phys 6:11-5, 1980.

232. WILKINSON JM: Interstitial radiotherapy at low dose rates. Br J Radiol 45:708, 1972.

233. WILKINSON JM, HENDRY JH, HUNTER RD: Doserate considerations in the introduction of low-doserate afterloading intracavitary techniques for radiotherapy. Br J Radiol 53:890-3, 1980.

234. WILLIS BK, HEILBRUN MP, SAPOZINK MD, MCDONALD PR: Stereotactic interstitial brachytherapy of malignant astrocytomas with remarks on postimplantation computed tomographic appearance. Neurosurgery 23:348-54, 1988.

235. WOOD JR, GREENE SB, SHAPIRO WR: The prognostic importance of tumor size in malignant gliomas: a computed tomographic scan study by the Brain Tumor Cooperative Group. J Clin Oncol 6:338-43, 1988.

236. WRONSKI M, ARBIT E, GALICICH JH, RUSSO P SOGANI P, FAIR WR: Surgical resection of brain metastases (BMET) from renal cell carcinoma (RCA): retrospective review of 50 patients. In Proceedings of the American Society of Clinical Oncology, 13:181, 1994. 
237. ZAMORANO L: Dose planning for interstitial irradiation. In Kelly PJ, Kall BA: Computers in stereotactic neurosurgery. Balckwell Scientific Publication, 1992.

238. ZIMM S, WAMPLER G, STABLEIN D, HAZRA T, YOUNG HF: Intracerebral metastases in solid-tumor patients: natural history and result of treatment. Cancer 41:384-94, 1981.
Original recebido em setembro de 2001 Aceito para publicação em janeiro de 2002

\section{Endereço para correspondência:}

Cláudio Fernandes Corrêa

Rua Condilac, 420/82

CEP 04116-270 - São Paulo, SP

E-mail: cfcorrea@uol.com.br 